\title{
PHYLOGENETIC RELATIONSHIPS OF THE TRIBE NEOSPARTONEAE (VERBENACEAE) BASED ON MOLECULAR DATA
}

\author{
Meng Lu' ${ }^{1}$, Laura A. Frost ${ }^{1}$, Nataly O'Leary $^{2}$ \& Richard G. Olmstead ${ }^{1}$
}

\author{
${ }^{1}$ Department of Biology and Burke Museum, University of Washington, Seattle, USA; olmstead@uw.edu (author \\ for correspondence). \\ ${ }^{2}$ Instituto de Botánica Darwinion, Labardén 200, Casilla de correo 22, 1642 San Isidro, Buenos Aires, Argentina.
}

\begin{abstract}
Lu, M.; L. A. Frost; N. O’Leary \& R. G. Olmstead. 2019. Phylogenetic relationships of the tribe Neospartoneae (Verbenaceae) based on molecular data. Darwiniana, nueva serie 7(2): 305-324.

Neospartoneae are a small tribe in Verbenaceae, native to temperate South America and comprising seven species in three genera: Diostea, Lampayo, and Neosparton. Diostea and Neosparton share an ephedroid habit and the presence of a staminode. Diostea and Lampayo share a schizocarpous fruit and bilobed stigma. Previous chloroplast DNA phylogenetic studies first identified Neospartoneae as a clade. However, evolutionary relationships within Neospartoneae remain unclear. In this study, nine loci from both chloroplast and nuclear genomes were used to reconstruct phylogeny with almost complete taxon sampling. Maximum likelihood and Bayesian analyses were conducted using single-locus and concatenated datasets to generate gene trees. A species tree was reconstructed by Bayesian multispecies coalescent analyses. The generic relationships are well resolved and confirm the monophyly of the Neospartoneae and each genus. The topologies show that Neosparton is sister to a clade comprised of Diostea and Lampayo. This study presents a first species-level phylogeny of Neospartoneae and provides insight into morphological character evolution of this tribe. The presence of a staminode shared by Diostea and Neosparton, and dry schizocarpous fruits shared by Diostea and Lampayo, are inferred to be plesiomorphic traits in Neospartoneae and not indicative of close relationship. The ephedroid habit and curved corolla tubes shared by Diostea and Neosparton may have evolved in the common ancestor of Neospartoneae and subsequently reversed in the ancestor of Lampayo, or have evolved in parallel in the two genera.
\end{abstract}

Keywords. Character evolution; Diostea; Flora of Argentina; Lampayo; molecular phylogeny; Neosparton; Neospartoneae; PPR.

Resumen. Lu, M.; L. A. Frost; N. O’Leary \& R. G. Olmstead. 2019. Relaciones filogenéticas en la tribu Neospartoneae (Verbenaceae) basadas en datos moleculares. Darwiniana, nueva serie 7(2): 305-324.

Neospartoneae es una pequeña tribu de Verbenaceae, nativa de Sudámerica templada, conformada por siete especies y tres géneros: Diostea, Lampayo y Neosparton. Diostea y Neosparton comparten el hábito efedroide y la presencia de un estaminodio. Diostea y Lampayo comparten el fruto esquizocárpico y el estigma bilobado. El clado Neospartoneae fue identificado por primera vez sobre la base de estudios filogéneticos a partir de ADN de cloroplasto. Sin embargo, las relaciones evolutivas dentro del clado permanecieron irresolutas. En el presente estudio se utilizan nueve loci, de cloroplasto y nucleares, para reconstruir la filogenia a partir de un muestreo de taxones casi completo. Para generar los árboles filogenéticos se llevaron a cabo análisis de máxima verosimilitud y bayesianos, empleando loci separados y concatenados. Se reconstruyó un árbol de especies empleando análisis bayesiano de coalescencia. Las relaciones genéricas estuvieron bien resueltas y se confirmó la monofilia de Neospartoneae y de cada género. Las topologías muestran que Neosparton es hermano de un clado 


\begin{abstract}
comprendido por Diostea y Lampayo. Este estudio representa la primera filogenia a nivel especie en Neospartoneae y provee información sobre la evolución de caracteres morfológicos en la tribu. El estaminodio presente en Diostea y Neosparton, y el fruto esquizocárpico seco compartido por Diostea y Lampayo, se infieren como caracteres plesiomórficos en Neospartoneae y no indican relación cercana. El hábito efedroide y los tubos corolinos curvos, compartidos por Diostea y Neosparton, pueden haber evolucionado en el ancestro común de Neospartoneae y luego revertido en el ancestro de Lampayo, o haber evolucionado en paralelo en ambos géneros.
\end{abstract}

Palabras clave. Diostea; evolución de caracteres; filogenia molecular; Flora Argentina; Lampayo; Neosparton; Neospartoneae; PPR.

\section{INTRODUCTION}

Verbenaceae are a family of flowering plants in the large asterid order Lamiales (Refulio \& Olmstead, 2014). The family is New World in origin and primarily Neotropical in distribution with a center of diversity in arid regions of southern South America (Marx et al., 2010; Múlgura et al., 2012). A small number of clades have dispersed to the Old World, primarily Africa, and into temperate zones in South and North America (Olmstead, 2013). Species in this family are trees, shrubs, lianas, and herbs with opposite leaves and slightly bilaterally symmetrical flowers with terminal or axillary inflorescences (Atkins, 2004). Fruits are fleshy or dry, generally dividing into two or four segments, with two or four seeds (O’Leary et al., 2012).

Recent publications suggest that Verbenaceae comprise about 35 genera and 830 species (Atkins, 2004; O'Leary et al., 2009, 2012; Thode et al., 2013). The tribal classification of Verbenaceae was revised by Marx et al. (2010) on the basis of a multi-locus molecular phylogeny and a new tribe Neospartoneae Olmstead \& N. O'Leary was first proposed being recognized as one of eight named tribes in Verbenaceae. They are sister to a major clade formed by tribes Lantaneae Endl., Verbeneae Dumort., and the genus Dipyrena Hook. Several tribes within Verbenaceae have been the subject of detailed phylogenetic study (Citharexyleae Briq. - Frost et al., 2017; Duranteae Benth. - Thode et al., 2013; Lantaneae - Lu-Irving \& Olmstead, 2013; Lu-Irving et al., 2014; Verbeneae - Yuan \& Olmstead, 2008a, b; O’Leary et al., 2009; Frost et al., 2017).
Plants in Neospartoneae typically are glabrous, have terminal spicate inflorescences (lateral in some Neosparton) comprised of sessile flowers with relatively long corolla tubes, much surpassing the calyx, and have fruits derived from unicarpellate ovaries consisting of two-seeded pyrenes. Neospartoneae are monophyletic (Marx et al., 2010), and comprise three genera, Diostea Mieres, Lampayo F. Phil. ex Murillo, and Neosparton Griseb. (Fig. 1). Neosparton includes three species endemic to the arid regions of Argentina. Plants of this genus are glabrous with cylindrical-striate stems similar to Ephedra, with reduced or ephemeral leaves. The genus Diostea is monotypic and distributed in the Patagonian regions of Argentina and Chile, represented normally by large shrubs and also exhibit an ephedroid habit. Lampayo comprises three species of the dry altiplano in Argentina, Bolivia, and Chile. These species are low spreading shrubs with fleshy leaves.

Traditional classifications of Verbenaceae often placed Diostea, Lampayo, and Neosparton in large polyphyletic tribes Lantaneae (Troncoso, 1974; Atkins, 2004) or Verbeneae (Sanders, 2001). The morphological traits among these three genera are mixed: Diostea and Neosparton share similarities in ephedroid habit, presence of a staminode (sometimes missing in Diostea), and curved corolla tubes, while Diostea and Lampayo have schizocarpous fruits and bilobed stigmas. Traditional classifications of Verbenaceae often relied heavily on fruit traits to delineate tribes, resulting in Neosparton being separated from Lampayo and Diostea (Atkins, 2004). Diostea was included without explanation as a synonym of Dipyrena Hook. by Ravenna (2008) before 

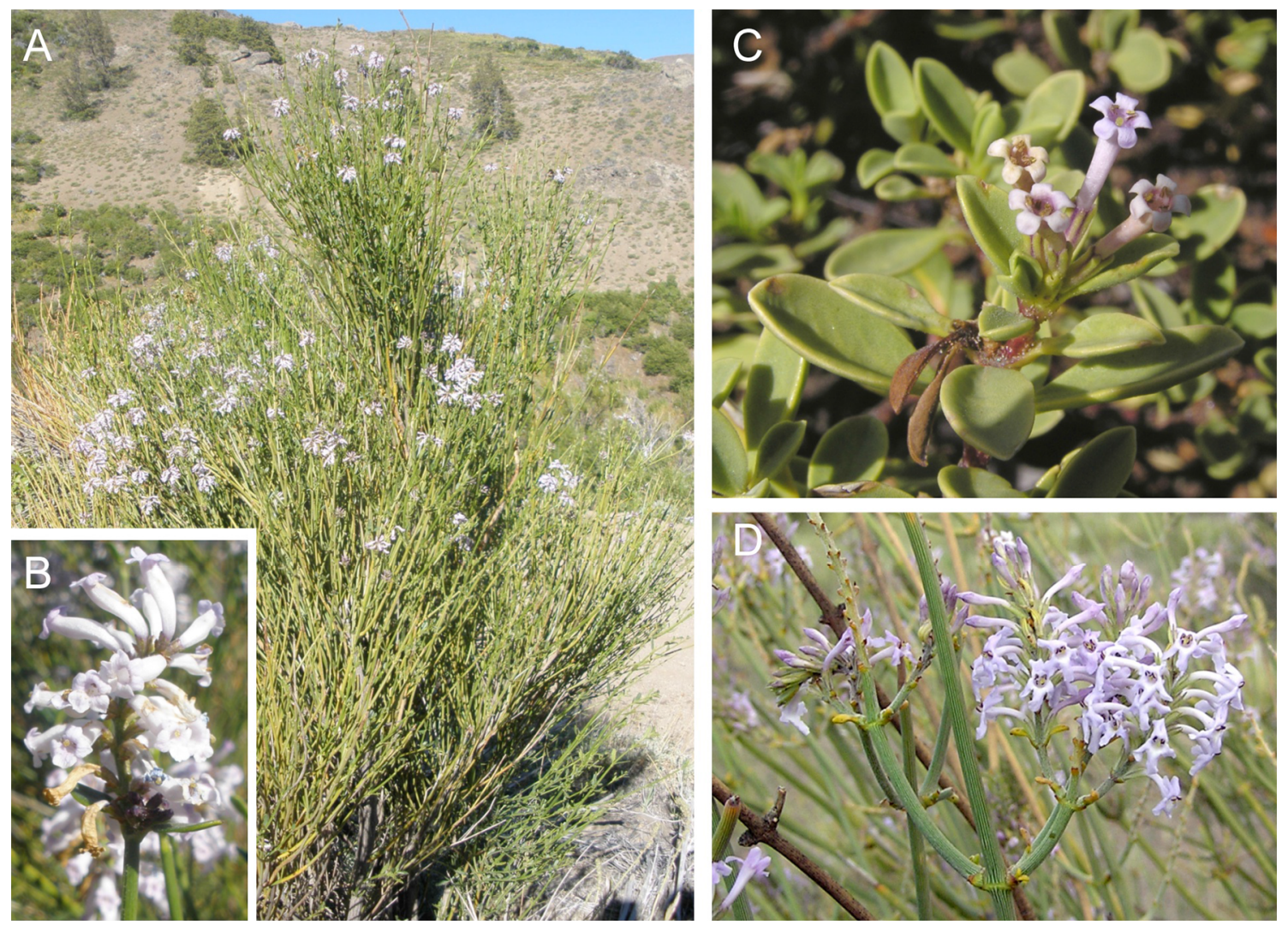

Fig. 1. Representative species of Neospartoneae. A, Diostea juncea habit. B, Diostea juncea inflorescence. C, Lampayo castellani. D, Neosparton aphyllum. All photos by R. Olmstead reused here with permission of the American Journal of Botany. Color version at http://www.ojs.darwin.edu.ar/index.php/darwiniana/article/view/841/1172

phylogenetic study showed that the two genera are not closely related (Marx et al., 2010). Both genera are recognized as monotypic in the Flora of Argentina (Múlgura et al., 2012). The evolutionary relationships among these three genera remain unclear. In the chloroplast DNA phylogeny of Verbenaceae (Marx et al., 2010), Diostea, Lampayo, and Neosparton are recognized as a monophyletic group for the first time with strong support. However, the limited DNA sequences and few samples in that study were unable to resolve the relationships within the new tribe and their results did not recover a monophyletic Lampayo.

This study presents a molecular phylogeny of tribe Neospartoneae. The almost complete taxonomic sampling includes all three genera and wide geographic representation. In total, 12 individuals from six species were included in this study.
Data are drawn from both chloroplast and nuclear genomes, so that they provide more robust molecular data than in previous studies. DNA sequence data from four chloroplast loci (trnLF, $n d h F, m a t K$, and $r b c L)$, the external and internal transcribed spacers (ETS/ ITS) regions of the nuclear ribosomal DNA (rDNA), and three loci of the nuclear pentatricopeptide repeat containing gene family (AT1G09680, AT3G09060, and AT5G39980; Yuan et al., 2009, 2010; Lu-Irving \& Olmstead, 2013), were used for the phylogenetic analyses. The goal of this study is to investigate whether each genus is monophyletic, resolve the phylogenetic relationships among Diostea, Lampayo, and Neosparton, to provide a more comprehensive understanding of the evolutionary patterns in Neospartoneae, and interpret the morphological changes among these three genera based on the reconstructed phylogenetic trees. 


\section{MATERIALS AND METHODS}

Twelve samples of Neospartoneae were included in this study, including six out of seven species in the clade. Only Neosparton patagonicum Tronc, a rare species endemic to southern Argentina, was not included. Except for Lampayo officinalis F. Phil. ex Murillo, all species are represented by multiple individuals spanning the geographic range of each species. Six outgroup species were selected based on the study of Marx et al. (2010). Detailed voucher information and collecting locations for all samples are listed in Table 1.

DNA was extracted from dried plant tissue (2$10 \mathrm{mg}$ ) using a modified CTAB method (Doyle \& Doyle, 1987) or by Qiagen DNeasy Plant Mini Kit (Qiagen, Valencia, California, USA) following the manufacturer's protocol. The tissue samples were from field collections preserved in silica gel, or from herbarium specimens.

PCR amplification reactions were performed in $25 \mu \mathrm{L}$ volumes with $1 \mu \mathrm{L}$ purified DNA, $0.125 \mu \mathrm{L}$ Taq DNA polymerase and prepared concentrations of $13.875 \mu \mathrm{L}$ sterile $\mathrm{dH} 2 \mathrm{O}, 2.5$ $\mu \mathrm{L}$ Taq Diluant, $2.5 \mu \mathrm{L} 10 \times$ PCR buffer with $\mathrm{MgCl}_{2}, 2.5 \mu \mathrm{L}$ dNTPs $(0.25 \mathrm{mM})$ and $1.25 \mu \mathrm{L}$ each of the forward and reverse primers $(5 \mu \mathrm{M})$. Reactions were run in a MJ Research (BioRad, Hercules, CA, USA) thermocycler under the following conditions: started at $94{ }^{\circ} \mathrm{C}$ for $2 \mathrm{~min}$; followed by 34 cycles of denaturation at $94{ }^{\circ} \mathrm{C}$ for $30 \mathrm{~s}$, annealing at $55{ }^{\circ} \mathrm{C}$ for $30 \mathrm{~s}$, and extension at $72{ }^{\circ} \mathrm{C}$ for $2 \mathrm{~min}$; and a final extension at $72{ }^{\circ} \mathrm{C}$ for $10 \mathrm{~min}$.

Four chloroplast DNA and five nuclear loci were targeted in this study. The chloroplast DNA loci and primers included $n d h F$ (Olmstead \& Reeves, 1995; Olmstead \& Sweere, 1994), trnL-F (Taberlet et al., 1991), matK (Sang et al., 1997; Bremer et al., 2002), and $r b c L$ (Olmstead et al., 1992). Targeted nuclear loci included two regions of ribosomal DNA and three pentatricopeptide repeat (PPR) loci (Yuan et al., 2009, 2010). The nuclear ribosomal internal transcribed spacer (ITS) was amplified with primer LL-ITS, and the ETS region was amplified by a universal primer, 18S-IGS (Baldwin \& Markos, 1998) and a Lamiales-specific primer, ETS-B (Beardsley et al., 2003). Lamiales-specific primers (Yuan et al., 2009, 2010) were used to amplify three PPR gene regions, AT1G09680 (hereafter referred as PPR 11), AT3G09060 (PPR 70), and AT5G39980 (PPR 123). Each PPR gene region was amplified in overlapping smaller fragments. All PCR products were cleaned by polyethylene glycol (PEG) precipitation.

The cleaned chloroplast DNA products were enriched by Sanger cycle sequencing which was performed following the standard Applied Biosystems protocol with BigDye v3.1 and PCR primers. The thermal cycler conditions were as follows: $94{ }^{\circ} \mathrm{C}$ for $2 \mathrm{~min}$, followed by 34 cycles of $94{ }^{\circ} \mathrm{C}$ for $15 \mathrm{~s}, 55^{\circ} \mathrm{C}$ for $15 \mathrm{~s}, 60{ }^{\circ} \mathrm{C}$ for 2 min, followed by $10^{\circ} \mathrm{C}$. Products of sequencing reactions were purified by precipitation in sodium acetate and ethanol, or by passing through Sephadex G-50 columns. Raw sequence data were generated by an Applied Biosystems genetic analyser ABI 3130 or 3730 Genetic Analyzer (Thermo Fisher Scientific, Grand Island, NY, USA). The cleaned nuclear DNA products were sequenced by GENEWIZ Inc. (South Plainfield, NJ) with the same primers used for PCR. Prior to sequencing, products were treated according to instructions provided by GENEWIZ for Sanger sequencing. Sequences were edited and assembled into contigs using Sequencher 4.7 (Gene Codes Corp.). Sites with multiple peaks were coded as ambiguities.

Newly obtained sequences were aligned with previously published sequences (Marx et al., 2010) using Geneious 9.1 (Biomatters, Ltd., Auckland, New Zealand). Both Akaike information criterion (AIC) and Bayesian Information Criterion (BIC) were calculated by jModeltest 2.1.4 (Guindon \& Gascuel, 2003; Darriba et al., 2012) to choose the best-fit model of substitution for each locus. The confidence for each model was set as 95\%; GTR + Gamma was selected as the best fitting model for each locus and was applied in all downstream phylogenetic analyses. 


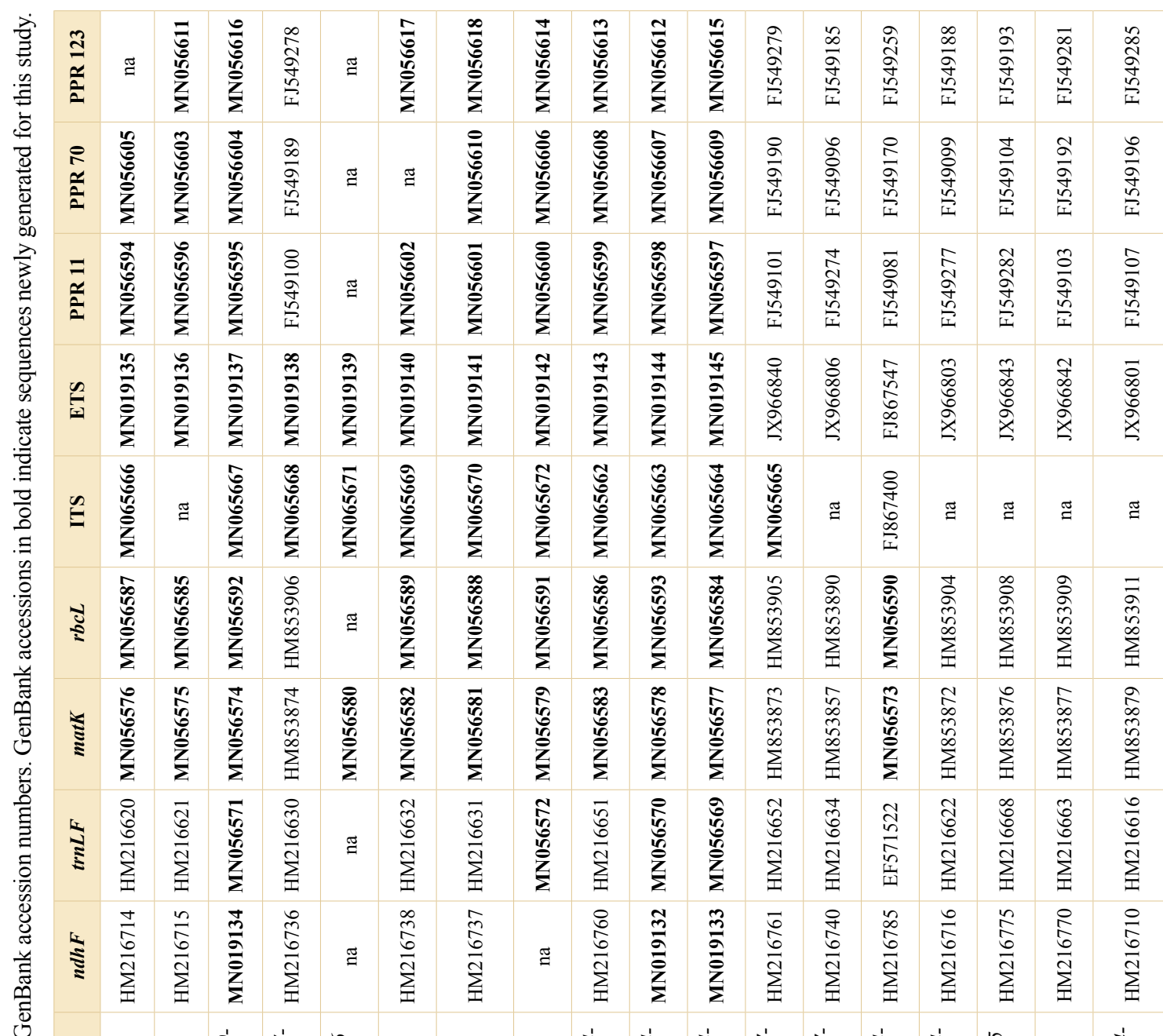

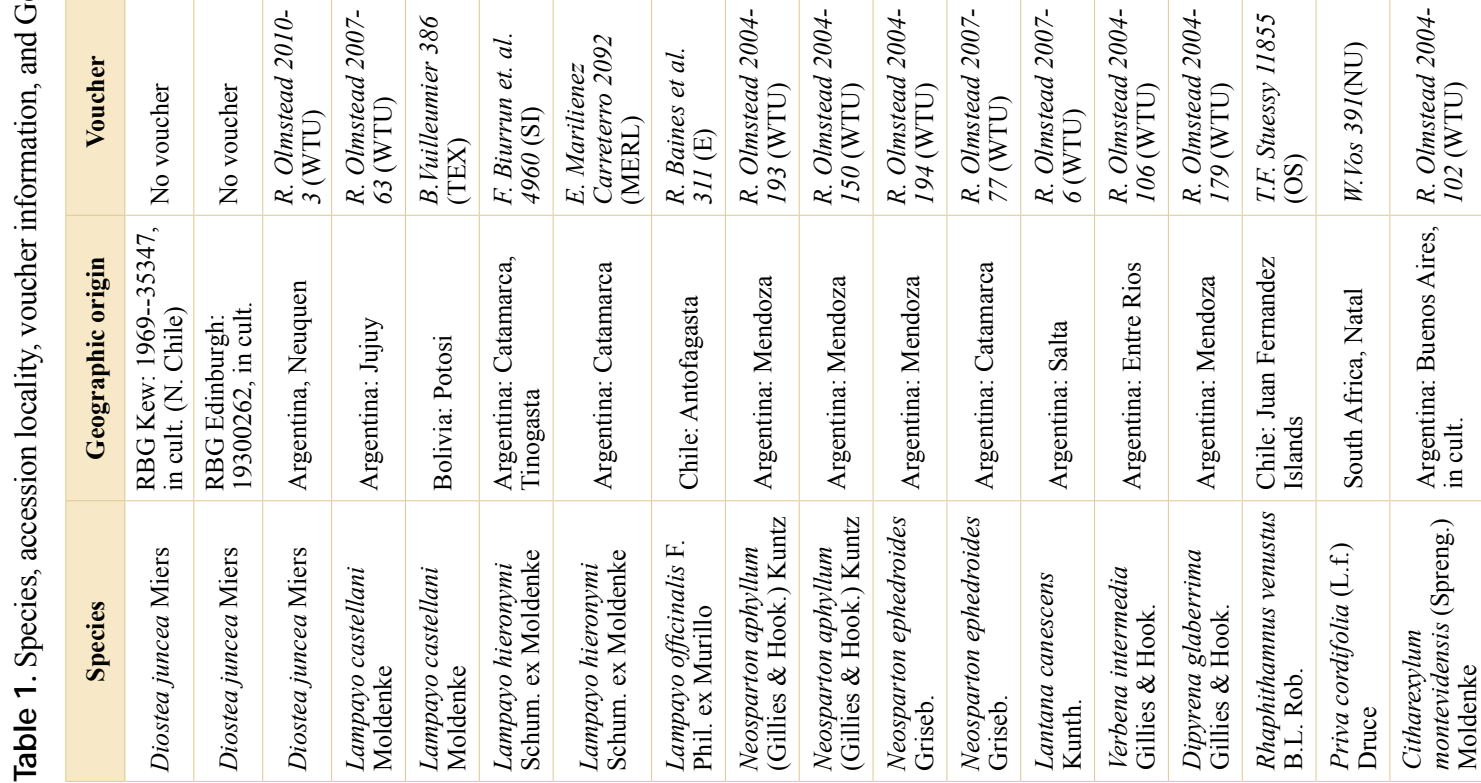


Regions with a shared evolutionary history [e.g., chloroplast regions ( $n d h F$, trnL-F, matK, and $r b c L$ ) and nuclear ribosomal spacers (ETS and ITS)] were combined and treated as a single locus for phylogenetic analysis. As such, five datasets were constructed for individual gene tree analysis: 1) combined four chloroplast loci (cpDNA); 2) two nuclear ribosomal loci (nrDNA); 3) $P P R$ 11; 4) PPR 70; and 5) PPR 123. All nine loci were also concatenated into one dataset and analyzed, which will be referred to as the "all combined" dataset.

Maximum likelihood analyses were run using Garli v2.0 (Zwickl, 2006; http://garli.googlecode.com). Two replicate runs were performed with 1000 generations of the generation threshold for termination. The score improvement threshold was set at 0.05 and the substitution rate model was set as gamma to include gamma-distributed rate variation. The rest of the parameters were set as the default. The condition would be satisfied if 100 replicates were performed or at least two replicates resulted in best-scoring trees with the same topology (Chau et al., 2017). Bootstraps were set as 100 replicates with 1000 generation termination condition. The results of bootstrap support values were added to the best trees which were run individually.

Bayesian analyses were performed in MrBayes 3.2.3 (Ronquist et al., 2012). For each dataset, two replicate runs with four chains were performed. Each run was set as 1 million generations and sampled every 100 generations. Convergence was assessed by checking the standard deviations of split frequencies in Tracer v1.5 (Rambaut \& Drummond, 2009). Chains were assessed in Tracer v1.5 (Rambaut \& Drummond, 2009), and the initial $10 \%$ sampled trees were discarded as burn-in. The consensus tree output was set as "all compatible". The analyses of concatenated datasets (cpDNA, nrDNA, and all combined datasets) were partitioned by locus and individual gene trees were examined to evaluate congruence with the all combined dataset.

A multispecies coalescent analysis was run using *BEAST (BEAST v1.8.1, Drummond et al., 2012). The multispecies coalescent model allows for specieslevel phylogenetic inference while accounting for gene tree discordance. Each individual sampled was assigned to its respective species for analysis.
Each of the nine loci were treated independently and each evolutionary model was set as unlinked and the GTR+gamma $(\mathrm{GTR}+\mathrm{G})$ model applied to each. The nucleotide base frequencies were estimated empirically from the data. For cpDNA and nrDNA datasets, trees were linked to reflect the shared evolutionary history of chloroplast regions and nuclear ribosomal spacers, respectively. To select the best-fit molecular clock model, analyses using three different models (strict clock, uncorrelated relaxed clock, and random local clock) were run and compared. The Log Bayes Factors under each clock model were calculated, and the final clock for each locus was set as random local clock with a uniform distribution. The species tree prior used the birth-death process. The length of MCMC chain was 250 million generations, and the sampling frequency was 25,000 generations. Chains were assessed in Tracer v1.5 (Rambaut \& Drummond, 2009), and the initial $10 \%$ of trees was discarded as burn-in. The stationarity of the log-likelihoods for each run was checked in Tracer v1.5 to evaluate the convergence. The maximum clade credibility tree was generated in TreeAnnotator v1.8.1 (Bouckaert et al., 2014).

Ancestral state reconstructions were performed with the *BEAST tree using maximum parsimony (MP), maximum likelihood (ML), and Bayesian inference (BI) for stigma lobing, corolla shape, fruit type, ephedroid habit, and staminodes. To better reconstruct the ancestral node for Neospartoneae, outgroup taxa representing Verbeneae, Lantaneae, Dipyrena, and Rhaphithamnus Miers - lineages with which Neospartoneae shares a recent common ancestor - were scored and included in ancestral state analyses. Parsimony reconstructions were performed using the "Trace Character History" > "Parsimony Ancestral States" function in Mesquite v3.51 (Maddison \& Maddison, 2018). Maximum likelihood and BI analyses were performed using BayesTraits v3 (Meade \& Pagel, 2016). For ML and BI analyses, the "Multistate" model of evolution was selected. Because the phylogeny included few data points (10 tips), a more informative prior was needed for BI analyses than the default uniform prior (range 0-100) on the instantaneous rates between states q01 and q10. Results of the ML analyses were used to inform those priors. Maximum likelihood ancestral state reconstructions consider branch lengths, and the estimates of transition rates between states are therefore influenced by branch lengths. 
The tree was scaled to reflect evolutionary time using estimated dates from a time-calibrated phylogeny of Lamiales (Tank \& Olmstead, unpublished). Edge lengths were multiplied by 126.9 using the ape package in R (Paradis et al., 2004; Paradis, 2012; Popescu et al., 2012). The resulting q01 and q10 estimates from the ML analyses were used to set the midpoint for exponential priors on q01 and q10 in $\mathrm{BI}$ analyses. Except for the transition rate prior, BI analyses were run with the default settings.

\section{RESULTS}

For the four chloroplast loci and ITS/ETS, complete or nearly complete sequences were obtained. In each case of a missing locus for an accession, at least one accession was sequenced for that locus for each species. Aligned lengths for individual loci were: $2086 \mathrm{bp}$ of $n d h F, 961 \mathrm{bp}$ of trnL-F, 1274 bp of $m a t K, 835$ bp of $r b c L, 671 \mathrm{bp}$ of ITS, $510 \mathrm{bp}$ of ETS, $1453 \mathrm{bp}$ of PPR 11, $1333 \mathrm{bp}$ of $P P R$ 70, and $1295 \mathrm{bp}$ of $P P R$ 123. All ingroup accessions, except one (L. castellani; Vuilleumier 386) were complete for at least eight of the nine loci sequenced. The length of the all combined dataset was 10,418 base pairs (bp). Each individual dataset contained 12 taxa (6 ingroups and 6 outgroups).

The maximum likelihood (ML) and Bayesian (BI) reconstructions for the ITS/ETS dataset produced the same topologies, but minor differences were observed between the ML and BI trees for the other loci. Monophyly of Neospartoneae and most clades corresponding to the three genera were supported by all individual loci with bootstrap values above $90 \%$ or posterior probabilities above 0.95 (Figs. S1-S6). The exceptions are that in the cpDNA trees from both analyses, Lampayo does not form a monophyletic group, with $L$. hieronymi appearing sister to Diostea. Topologies varied among individual nuclear gene trees. Lampayo is sister to Neosparton in both ITS/ETS analyses, the ML analysis of $P P R 11$, and the $\mathrm{BI}$ analysis of $P P R 123$. Lampayo is sister to Diostea in both analyses of $P P R$ 70 , the $\mathrm{BI}$ analysis of $P P R 11$, and the ML analysis of $P P R$ 123. None of these intergeneric relationships are well-supported and none of the individual gene trees supported Diostea as sister to Neosparton.
Both analyses of the all combined dataset produced trees that are congruent with respect to relationships within Neospartoneae (Fig. 2). According to the analyses based on the all combined dataset each genus is monophyletic with strong support and Lampayo is sister to Diostea with moderate support.

The species tree generated under the multispecies coalescent model confirmed that all three genera were monophyletic with strong support (Fig. 3). The species tree was congruent with the topology from the concatenated DNA sequence tree from the all combined dataset, including that Lampayo was sister to Diostea, with strong support.

States for each morphological trait were unambiguously assigned for each tip in the phylogeny, except for fruit type in Lantaneae, which have both dry and fleshy fruits, so were coded for both. Most nodes within Neospartoneae were reconstructed with strong support in ML and BI analyses (likelihood $>70 \%$ and posterior probability $>0.95$, respectively) and without ambiguity in MP analyses (Table S1). Bilobed stigmas and staminodes were inferred to be ancestral within Neospartoneae and lost in Neosparton and Lampayo, respectively. Corolla shape, fruit type, and ephedroid habit had ambiguous ancestral reconstructions at the crown node of Neospartoneae, with corolla shape and ephedroid habit also uncertain in the common ancestor of Diostea and Lampayo (Fig. S7).

Maximum parsimony analyses found bilobed stigmas tobe present in the ancestor of Neospartoneae. Unlobed stigmas arose in Neosparton (Fig. 3; Fig. S7). A similar pattern was likely for fruit evolution; dry fruits were present in the ancestor and fleshy fruits arose in Neosparton. However, the reconstruction of fruit type was ambiguous (Table S1) in the ancestor to Neospartoneae due to outgroup sampling (see discussion below). Curved corollas, ephedroid habit, and staminodes share the same pattern in extant Neospartoneae: present in Neosparton and Diostea, absent in Lampayo. Staminodes were inferred to be present in the ancestor of Neospartoneae and subsequently lost in Lampayo. Maximum likelihood analysis of ancestral states, found relatively strong support for the presence of curved corollas and ephedroid habit in the ancestor of Neospartoneae (Table S1). 


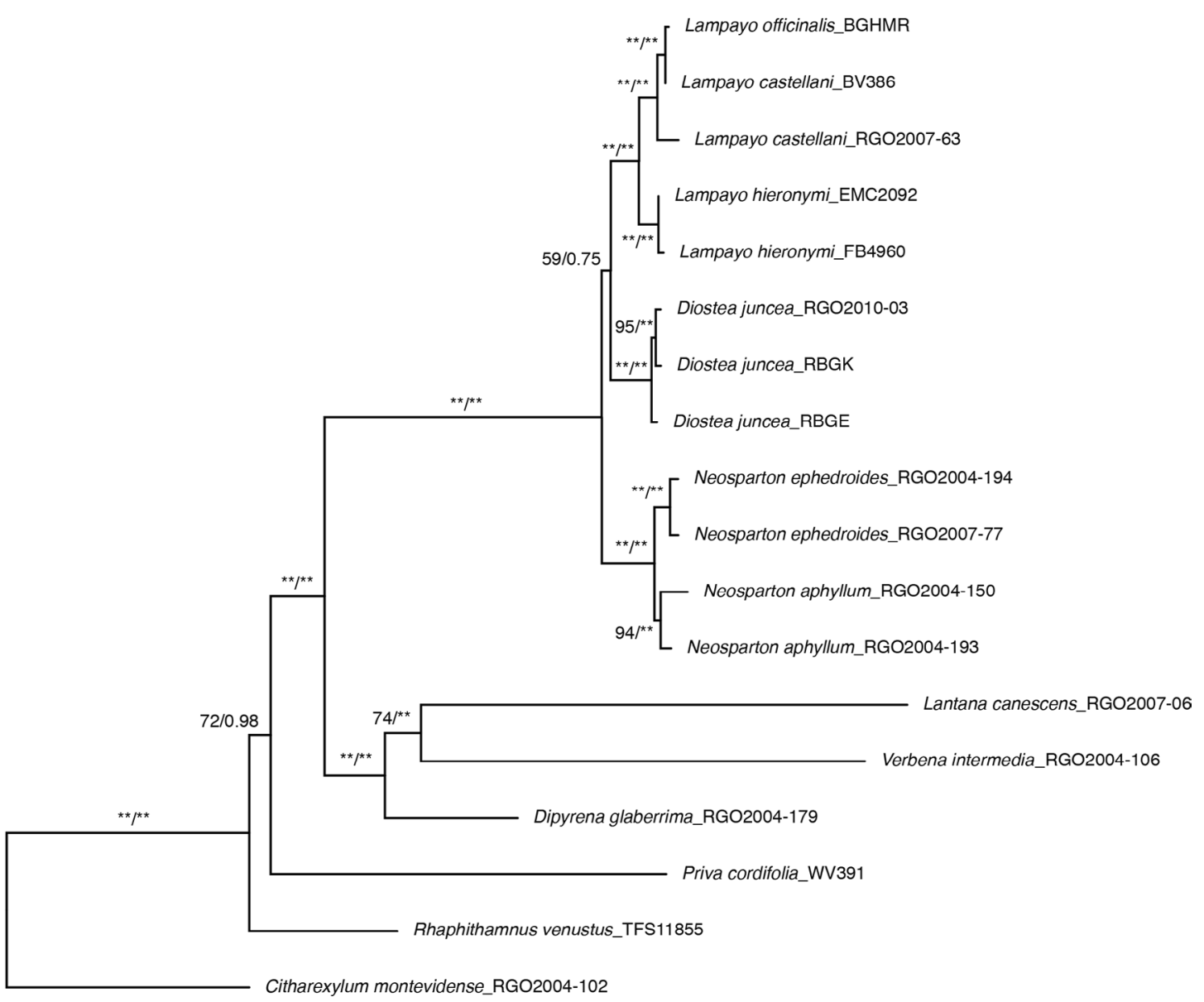

Fig. 2. Phylogeny of Neospartoneae based on a concatenated, nine-gene dataset. Numbers on branches are ML bootstrap and BI posterior probabilities (** indicates $100 \%$ bootstrap or posterior probability of 1.0 ).

\section{DISCUSSION AND CONCLUSIONS}

\section{Phylogeny of Neospartoneae}

This study presents the most complete specieslevel molecular phylogeny of Neospartoneae. Analysis of a multi-locus dataset, including representative outgroups from other tribes in Verbenaceae, found Neospartoneae to be a wellsupported clade, confirming results of Marx et al. (2010) based on plastid DNA data. The tree based on concatenated data from all nine loci and the species tree based on a coalescent model show congruence in relationships among genera and species. The taxon sampling for this study includes the rarely collected species Lampayo officinalis, but does not include another rare species, Neosparton patagonicum.
Phylogenetic reconstructions from both the concatenated data and species tree analyses show that Diostea, Lampayo, and Neosparton are each monophyletic. A previous chloroplast DNA study (Marx et al., 2010) did not provide clear resolution for relationships within the Neospartoneae, and Lampayo was not found to be monophyletic. Our results based on chloroplast data alone also inferred a paraphyletic Lampayo (Fig. S1). In contrast, all of the individual nuclear gene trees obtained a monophyletic Lampayo (Figs. S2-S6), ML and BI analyses of the all combined dataset as well as the species tree from the multispecies coalescent analysis also support a monophyletic Lampayo (Figs. 2-3). 

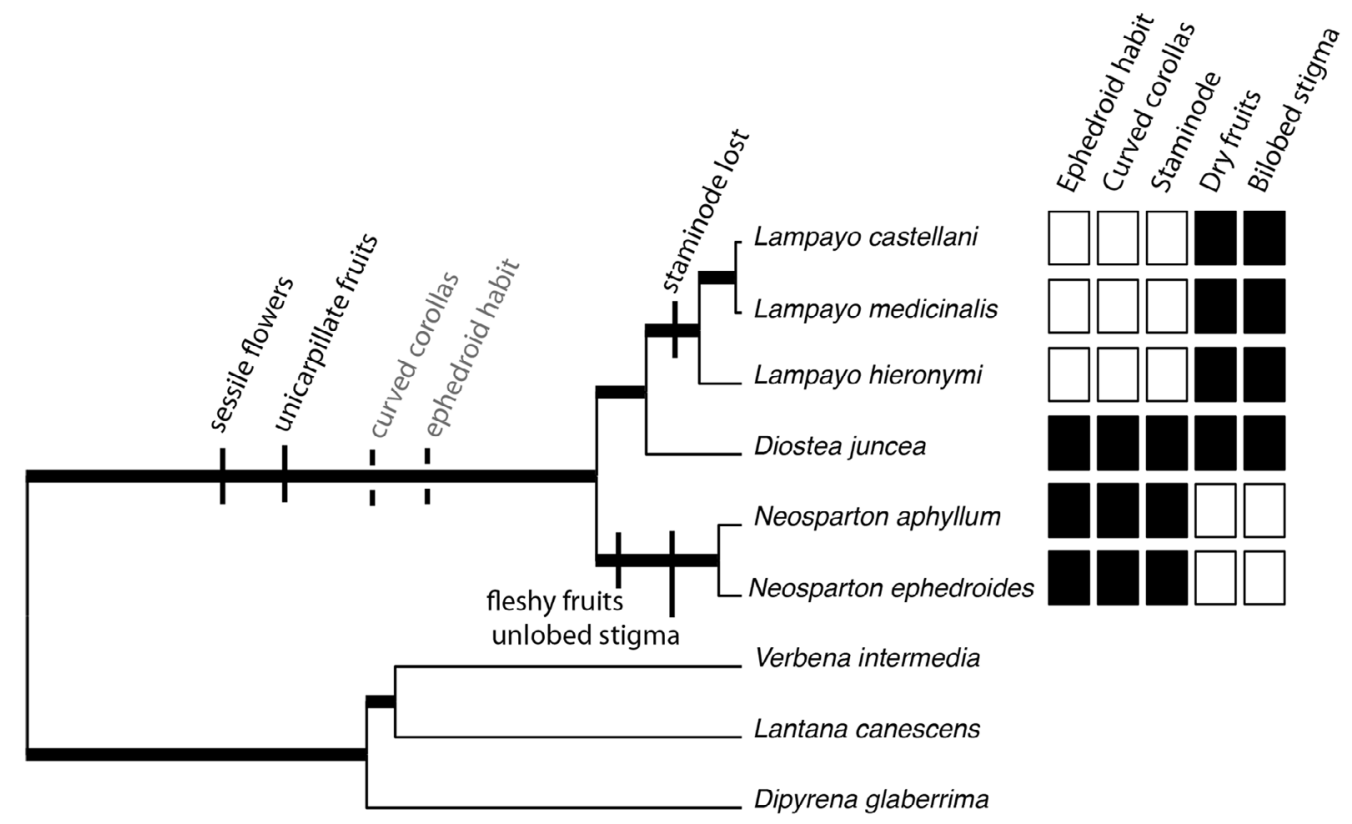

Fig. 3. Phylogeny of Neospartoneae based on coalescent species tree for nine genes partitioned into five independent loci (cpDNA, nrDNA, PPR 11, PPR 70, PPR 123). Inferred character reconstructions noted on branches; solid crosslines and dark font for unambiguous reconstructions, dashed crosslines and gray font for reconstructions with likelihoods $>80 \%$. Bold branches indicate Bayesian posterior probability $>0.95$.

Both concatenated gene tree and species tree results are consistent with regard to generic relationships within Neospartoneae. Diostea is sister to Lampayo and together they form a clade sister to Neosparton (Figs. 2-3). Incongruence exists among individual gene trees from different loci, but the nodes supporting generic relationships receive low to moderate support in all individual gene trees. Poor resolution is more likely in rapid radiations (Whitfield \& Lockhart, 2007), but factors such as hybridization and introgression or incomplete lineage sorting cannot be ruled out. The low support for conflicting gene trees suggests a history of incomplete coalescence, or simply the inability of small data samples in some individual gene trees to correctly reconstruct phylogenetic history (Degnan \& Rosenberg, 2009).

In all cases, with one exception, multiple accessions of individual species group together in the concatenated data gene tree. Within Lampayo, our single accession of $L$. officinalis is nested within the samples of $L$. castellani in the all combined dataset results. However, only the chloroplast and ITS/ETS datasets included both accessions of $L$. castellani, and the L. officinalis specimen grouped with different accessions of $L$. castellani in each of those gene trees with short internode lengths and low support in the cpDNA tree, suggesting a very recent common ancestry for the two species. A review of available herbarium specimens shows clear differences between the two species in leaf and floral morphology, supporting maintaining two distinct species $(\mathrm{N}$. O’Leary, personal observation).

\section{Morphological Evolution}

A study of morphological traits in Verbenaceae identified two prospective synapomorphies of Neospartoneae, sessile flowers and unicarpellate fruits (O'Leary et al., 2012). We infer two additional prospective synapomorphies: curved corollas and ephedroid habit. Within Neospartoneae, Diostea and Neosparton share an ephedroid habit, with photosyntheticstemsandreduced, ephemeralleaves, and flowers with elongate, curved corolla tubes. 
In contrast, Lampayo is a leafy shrub with unusually thick (for Verbenaceae) fleshy leaves and flowers with straight corollas. In the case of both curved corollas and ephedroid habit, the likelihood analysis of their evolution indicates a higher probability $(\mathrm{p}=0.813)$ of these traits being ancestral in Neospartoneae and retained in Diostea and Neosparton, while being transformed in Lampayo to the leafy shrubs with straight corollas that we see today.

O'Leary etal.(2012) performed reconstructions of character evolution for stigma characters, fruit type, and staminodes across Verbenaceae, demonstrating that the history of carpel and fruit evolution is more complex in this family than traditional classifications would suggest. Broader taxonomic sampling in that study provided greater resolution for fruit evolution. O'Leary et al. (2012) found that a reduction in carpel number in the common ancestor of the three genera was followed by the evolution of fleshy fruits in Neosparton, while the dry schizocarpous fruits of Diostea and Lampayo are retained from the common ancestor of the tribe. This finding concerning the origin of fleshy fruits in Neosparton was weakly supported by our analyses, but this was because of limited outgroup sampling in this study; thus these results do not conflict with those of O'Leary et al. (2012). As with dry fruits, bilobed stigmas and the presence of a staminode are plesiomorphic traits in Neospartoneae, with the evolution of an unlobed stigma in Neosparton and the loss of the staminode in Lampayo, respectively.

The shared ephedroid habit of Diostea and Neosparton is derived in Neospartoneae, suggesting that this unusual morphology evolved in the common ancestor of Neospartoneae, and may be another synapomorphy for the tribe. However, that history cannot be confirmed by our results. We cannot rule out that it evolved independently in each genus (it is also found in some distantly related Verbenaceae, e.g., some species of Junellia Moldenke). Lampayo has a leafy habit, although with fleshy leaves that are unusual in Verbenaceae, suggesting that leafy habit may have reappeared in Lampayo.
Similarly, the curved corollas shared by Diostea and Neosparton are unusual in Verbenaceae and probably derived within Neospartoneae and may represent another synapomorphy that is reversed in Lampayo.

Thus, of the five variable traits that might suggest relationships among the three genera (ephedroid habit, presence of a staminode, curved $v s$. straight corolla tubes, bilobed vs. unlobed stigmas, and fleshy vs. dry fruit) all are either autapomorphic within Neospartoneae (loss of staminode, unlobed stigma, fleshy fruit), or represent a synapomorphy for the clade that is reversed in Lampayo (ephedroid habit, curved corollas) and none provide supporting morphological evidence of the relationship among the three genera inferred here based on DNA sequences.

\section{Conclusions}

Neospartoneae are a small clade of Verbenaceae distributed primarily in Argentina, but with distributions extending into Chile and Bolivia, where one species (Lampayo officinalis) occurs exclusive of Argentina. With only seven species, Neospartoneae form the sister group to the widespread and species rich clade comprising tribes Lantaneae and Verbeneae. Sessile flowers and a single carpel have been identified as synapomorphies of Neospartoneae (O'Leary et al., 2012), with ephedroid habit and curved corollas as additional potential synapomorphies, although convergent evolution of those traits cannot be ruled out.

\section{ACKNOWLEDGEMENTS}

The authors thank the Royal Botanical Gardens at Edinburgh and Kew for providing plant material and the curators of following herbaria for permitting sampling of specimens for DNA analysis: E, MERL, NU, OS, SI, TEX. We thank the American Journal of Botany for permission to reuse figure 1 (Marx et al., 2010). This research was supported by NSF grants DEB 1020369 and DEB 1500919. We also thank Veronica Thode and one anonymous reviewer for valuable comments on the manuscript. 


\section{BIBLIOGRAPHY}

Atkins, S. 2004. Verbenaceae, in J. W. Kadereit (ed.), The families and genera of flowering plants, vol. 7, 449-468. Berlin, Germany: Springer-Verlag.

Baldwin, B. G. \& S. Markos. 1998. Phylogenetic utility of the external transcribed spacer (ETS) of 18S-26S rDNA: congruence of ETS and ITS trees of Calycadenia (Compositae). Molecular Phylogenetics and Evolution 10: 449-463.

Beardsley P. M., A. Yen, \& R. G. Olmstead. 2003. AFLP phylogeny of Mimulus section Erythranthe and the evolution of hummingbird pollination. Evolution 57: 1397-1410.

Bouckaert, R., Heled, J., Kühnert, D., Vaughan, T., Wu, C-H., Xie, D., Suchard, M. A., Rambaut, A., \& Drummond, A. J. 2014. BEAST 2: A Software Platform for Bayesian Evolutionary Analysis. PLoS Computational Biology 10(4): e1003537.

Bremer, B., K. Bremer, N. Heidari, P. Erixon, R. G. Olmstead, A. A. Anderberg, M. Kallersjo, \& E. Barkhordarian. 2002. Phylogenetics of asterids based on 3 coding and 3 non-coding chloroplast DNA markers and the utility of non-coding DNA at higher taxonomic levels. Molecular Phylogenetics and Evolution 24: 274-301.

Chau, J. H., N. O'Leary, W.-B. Sun, \& R. G. Olmstead. 2017. Phylogenetic relationships in tribe Buddlejeae (Scrophulariaceae) based on nuclear and plastid markers. Botanical Journal of the Linnean Society 184:137-166.

Darriba, D., G. L. Taboada, R. Doallo, \& D. Posada. 2012. jModel-Test 2:more models, new heuristics and parallel computing. Nature Methods 9: 772.

Degnan J. H. \& N. A. Rosenberg. 2009. Gene tree discordance, phylogenetic inference and the multispecies coalescent, Trends in Ecology \& Evolution 24: 332-340.

Doyle J. J. \& J. L. Doyle. 1987. A rapid DNA isolation procedure for small quantities of fresh leaf tissue. Phytochemical Bulletin, Botanical Society of America 19: 11-15.

Drummond, A. J., M. A. Suchard, D. Xie, \& A. Rambaut. 2012. Bayesian phylogenetics with BEAUti and the BEAST 1.7. Molecular Phylogenetics and Evolution 29: 1969-1973.

Frost, L. A., S. McAdams Tyson, P. Lu-Irving, N. O’Leary, \& R. G. Olmstead. 2017. Origins of North American arid-land Verbenaceae: more than one way to skin a cat. American Journal of Botany 104: 1708-1716.

Guindon, S. \& O. Gascuel. 2003. A simple, fast, and accurate algorithm to estimate large phylogenies by maximum likelihood. Systematic Biology 52: 696-704.

Lu-Irving, P. \& R. G. Olmstead. 2013. Investigating the evolution of Lantaneae (Verbenaceae) using multiple loci. Botanical Journal of the Linnean Society 171: 103-119.
Lu-Irving, P., N. O’Leary, A. O’Brien, \& R. G. Olmstead. 2014. Resolving the genera Aloysia and Acantholippia within the tribe Lantaneae (Verbenaceae), using chloroplast and nuclear sequence data. Systematic Botany 39: 644-655.

Maddison, W. P. \& D. R. Maddison. 2018. Mesquite: a modular system for evolutionary analysis. Version 3.51, http://www. mesquiteproject.org

Marx, H., N. O’Leary, Y.-W. Yuan, P. Lu-Irving, D. Tank, M. Múlgura, \& R. G. Olmstead. 2010. A molecular phylogeny and classification of Verbenaceae. American Journal of Botany 97(10): 1647-1663.

Meade, A. \& M. Pagel. 2016. BayesTraits V3. http://www. evolution.rdg.ac.uk/BayesTraitsV3.0.1/BayesTraitsV3.0.1.html

Múlgura, M. E., N. O’Leary, \& A. D. Rotman. 2012. Verbenaceae, in F. O. Zuloaga \& A. M. Anton (eds.), Flora Argentina 14: i-v + 1-220. Buenos Aires: Estudio Sigma.

O’Leary, N., C. I. Calviño, S. Martínez, P. Lu-Irving, R. G. Olmstead, \& M. E. Múlgura. 2012. Evolution of morphological traits in Verbenaceae. American Journal of Botany 99: 1778-1792.

O’Leary N, Y.-W. Yuan, A. Chemisquy, \& R. G. Olmstead. 2009. Reassignment of species of paraphyletic Junellia s.1. to the new genus Mulguraea (Verbenaceae) and new circumscription of genus Junellia: molecular and morphological congruence. Systematic Botany 34: 777-786.

Olmstead, R. G. 2013. Phylogeny and biogeography in Solanaceae, Verbenaceae, and Bignoniaceae: a comparision of continental and intercontinental diversification patterns. Botanical Journal of the Linnean Society 171: 80-102.

Olmstead R. G. \& P. A. Reeves. 1995. Evidence for the polyphyly of the Scrophulariaceae based on chloroplast $r b c L$ and $n d h F$ sequences. Annals of the Missouri Botanical Garden 82: 176-193.

Olmstead R. G. \& J. A. Sweere. 1994. Combining data in phylogenetic systematics: an empirical approach using three molecular data sets in the Solanaceae. Systematic Biology 43: 467-481.

Olmstead, R. G., H. J. Michaels, K. Scott, \& J. D. Palmer. 1992. Monophyly of the Asteridae and identification of their major lineages inferred from DNA sequences of rbcL. Annals of the Missouri Botanical Garden 79: 249-265.

Paradis, E. 2012 Analysis of Phylogenetics and Evolution with $R$ (Second Edition). New York: Springer.

Paradis, E., Claude, J. \& K. Strimmer. 2004 APE: analyses of phylogenetics and evolution in R language. Bioinformatics 20: 289-290.

Popescu, A.-A., Huber, K. T. \& E. Paradis. 2012. Ape 3.0: new tools for distance based phylogenetics and evolutionary analysis in R. Bioinformatics 28: 1536-1537. 
Rambaut, A. \& A. J. Drummond. 2009. Tracer, version 1.5. Available at http://tree.bio.ac.uk/software/tracer

Ravenna, P. F. 2008. Studies in Verbenaceae V. Dipyrena Hook., a valid genus antedating Diostea Miers, including a new species and transfers. Onira 11(15): 40-44.

Refulio, N. F. \& R. G. Olmstead. 2014. Phylogeny of Lamiidae. American Journal of Botany 101: 287-299.

Ronquist, F., M. Teslenko, P. van der Mark, D. L. Ayres, A. Garling, S. Höhna, B. Larget, L. Liu, M. A. Suchard, \& J. P. Huelsenbeck. 2012. MrBayes 3.2: efficient Bayesian phylogenetic inference and model choices across a large model space. Systematic Biology 61: 539-542.

Sanders R. W. 2001. The genera of Verbenaceae in the southeastern United States. Harvard Papers in Botany 5: 303-358.

Sang, T., D. J. Crawford, \& T. F. Stuessy. 1997. Chloroplast DNA phylogeny, reticulate evolution, and biogeography of Paeonia (Paeoniaceae). American Journal of Botany 84: 1120-1136.

Taberlet P., L. Gielly, G. Pautou, \& J. Bouvet. 1991. Universal primers for amplification of three non-coding regions of chloroplast DNA. Plant Molecular Biology 17: 1105-1109.

Thode, V. A., N. O’Leary, R. G. Olmstead, \& L. B. Freitas. 2013. Phylogenetic position of the monotypic genus Verbenoxylum (Verbenaceae) and new combination under Recordia. Systematic Botany 38: 805-817.
Troncoso, N. S. 1974. Los géneros de Verbenaceas de sudamerica extratropical (Argentina, Chile, Bolivia, Paraguai, Uruguaiy sur de Brasil). Darwiniana 18: 295-412.

Whitfield, J. B. \& P. J. Lockhart. 2007. Deciphering ancient rapid radiations. Trends in Ecology \& Evolution 22: 258-265

Yuan, Y.-W., C. Liu, H. E. Marx, \& R. G. Olmstead. 2009. The pentatricopeptide repeat (PPR) gene family, a tremendous resource for plant phylogenetic studies. New Phytologist 182: 272-283.

Yuan, Y.-W., C. Liu, H. E. Marx, \& R. G. Olmstead. 2010. An empirical demonstration of using pentatricopeptide repeat (PPR) genes as plant phylogenetic tools: phylogeny of Verbenaceae and the Verbena complex. Molecular Phylogenetics and Evolution 54: 23-35.

Yuan Y.-W. \& R. G. Olmstead. 2008a. A species-level phylogenetic study of the Verbena complex (Verbenaceae) indicates two independent intergeneric chloroplast transfers. Molecular Phylogenetics and Evolution 48: 23-33.

Yuan Y.-W. \& R. G. Olmstead. 2008b. Evolution and phylogenetic utility of the PHOT gene duplicates in a recently diversified group: Dramatic intron size variation and footprint of ancestral recombination. American Journal of Botany 95: 1166-1176.

Zwickl, D. J. 2006. Genetic algorithm approaches for the phylogenetic analysis of large biological sequence datasets under them maximum likelihood criterion. Ph.D. diss., University of Texas, Austin. 


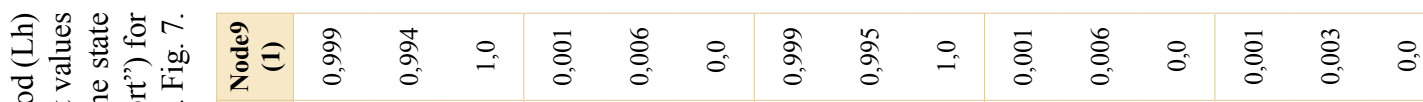

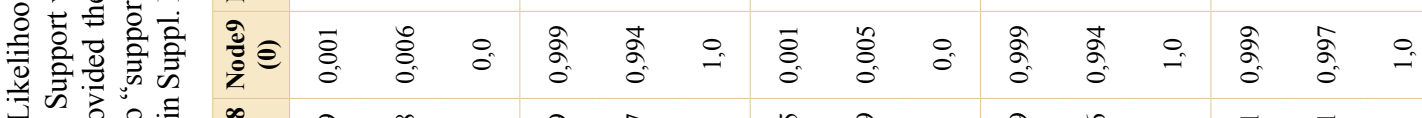

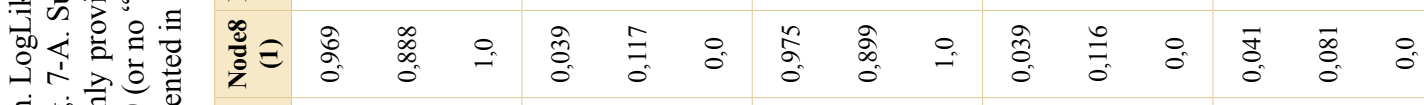

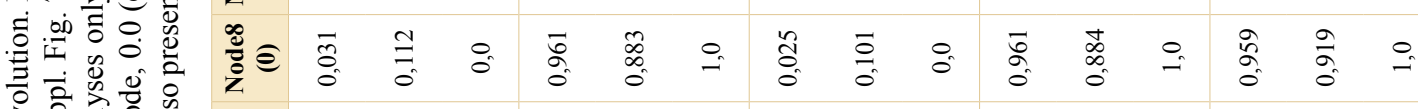

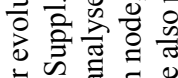

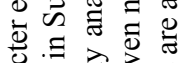

尊

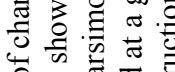

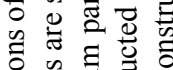

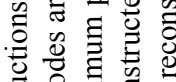

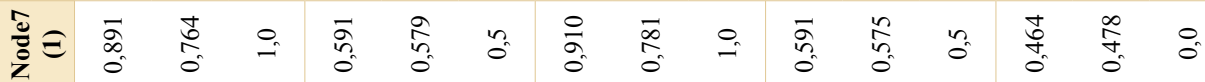

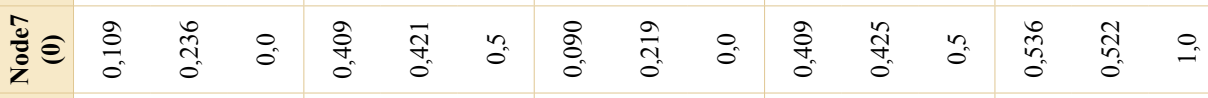

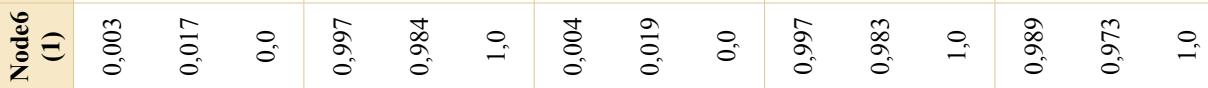

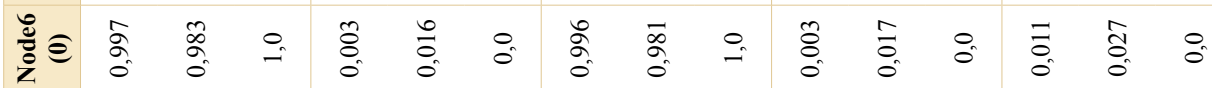
咅部曾

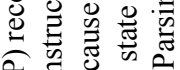

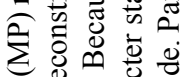
空

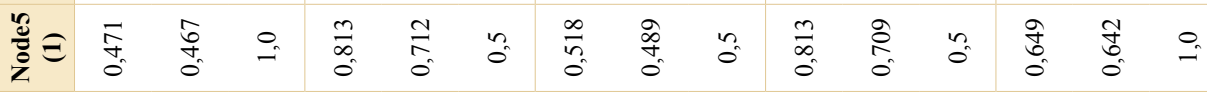

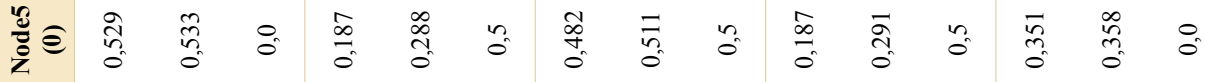

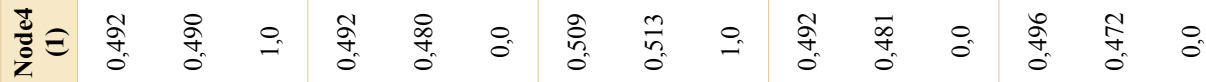

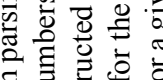

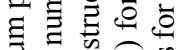

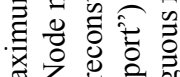

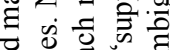

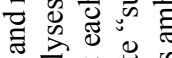

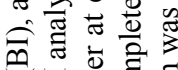
急

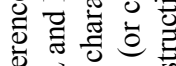

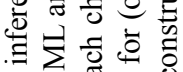
是 s.

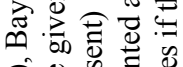

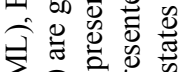

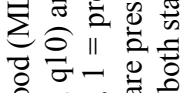

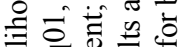

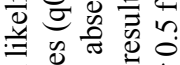

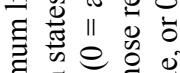

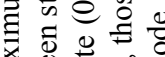

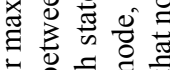

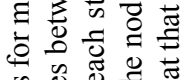

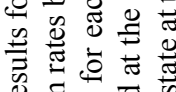

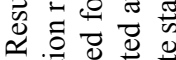

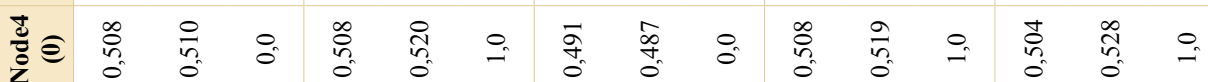

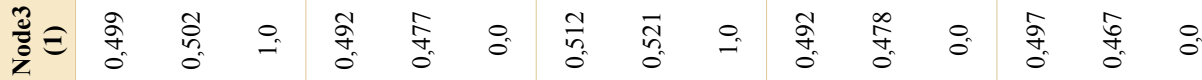

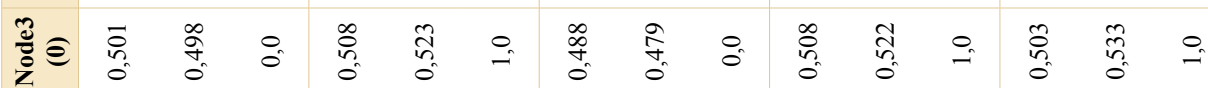

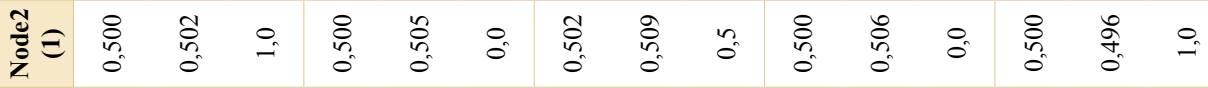

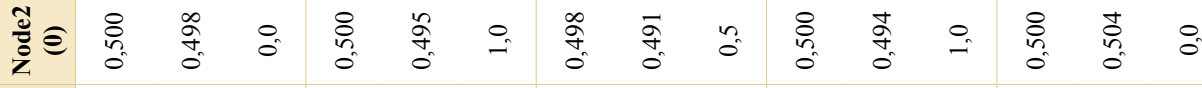

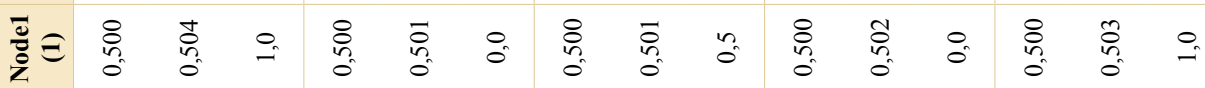

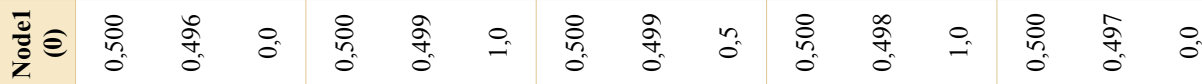

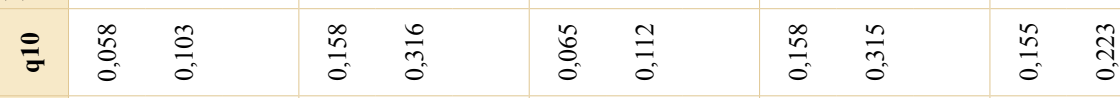

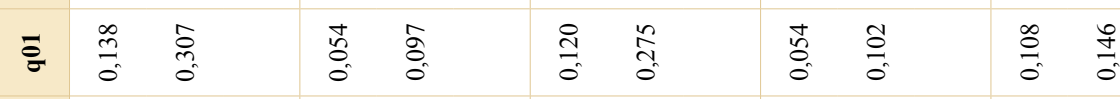

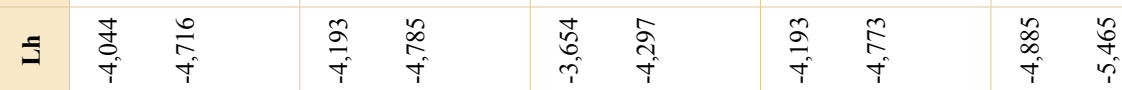

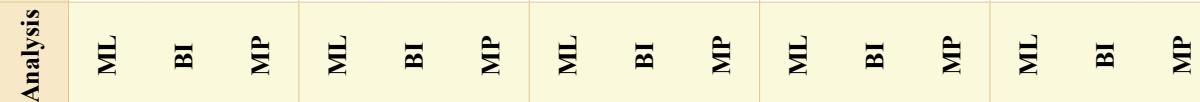

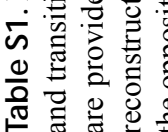


DARWINIANA, nueva serie 7(2): 305-324. 2019

ML

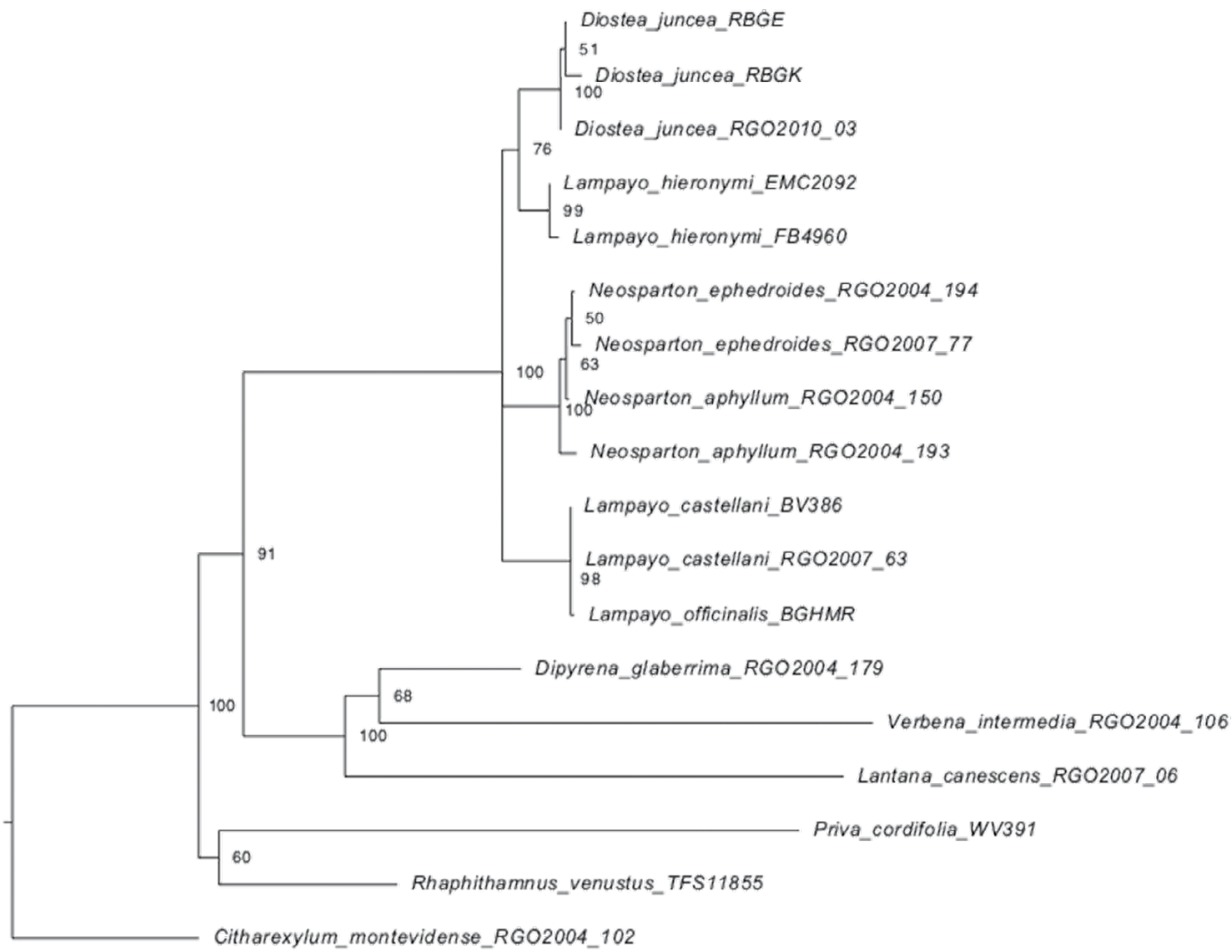

BI

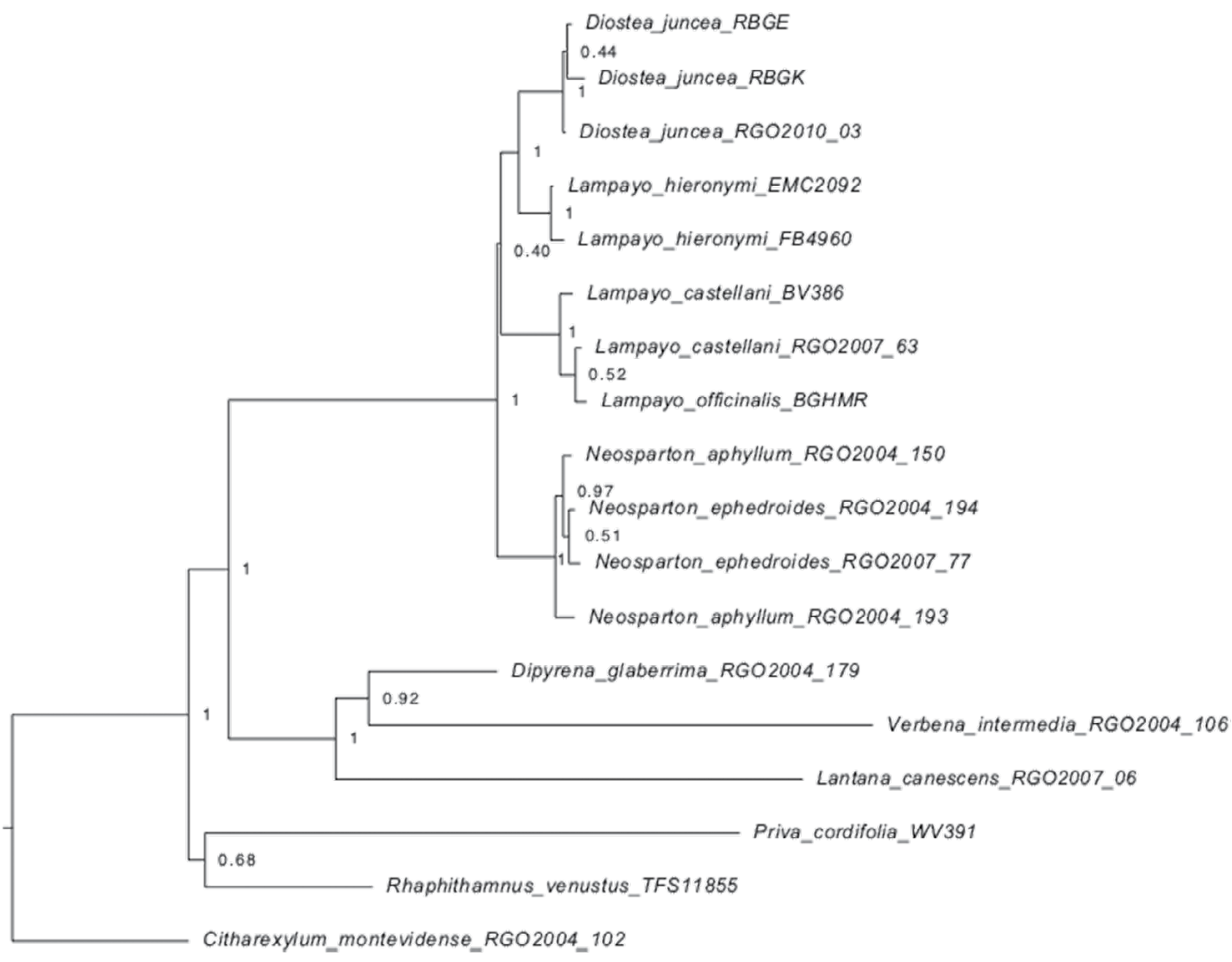

Fig. S1. Maximum likelihood tree (above) and Bayesian tree (below) for concatenated chloroplast loci. 
M. LU ET AL. Phylogeny of Neospartoneae (Verbenaceae)

$\mathrm{ML}$

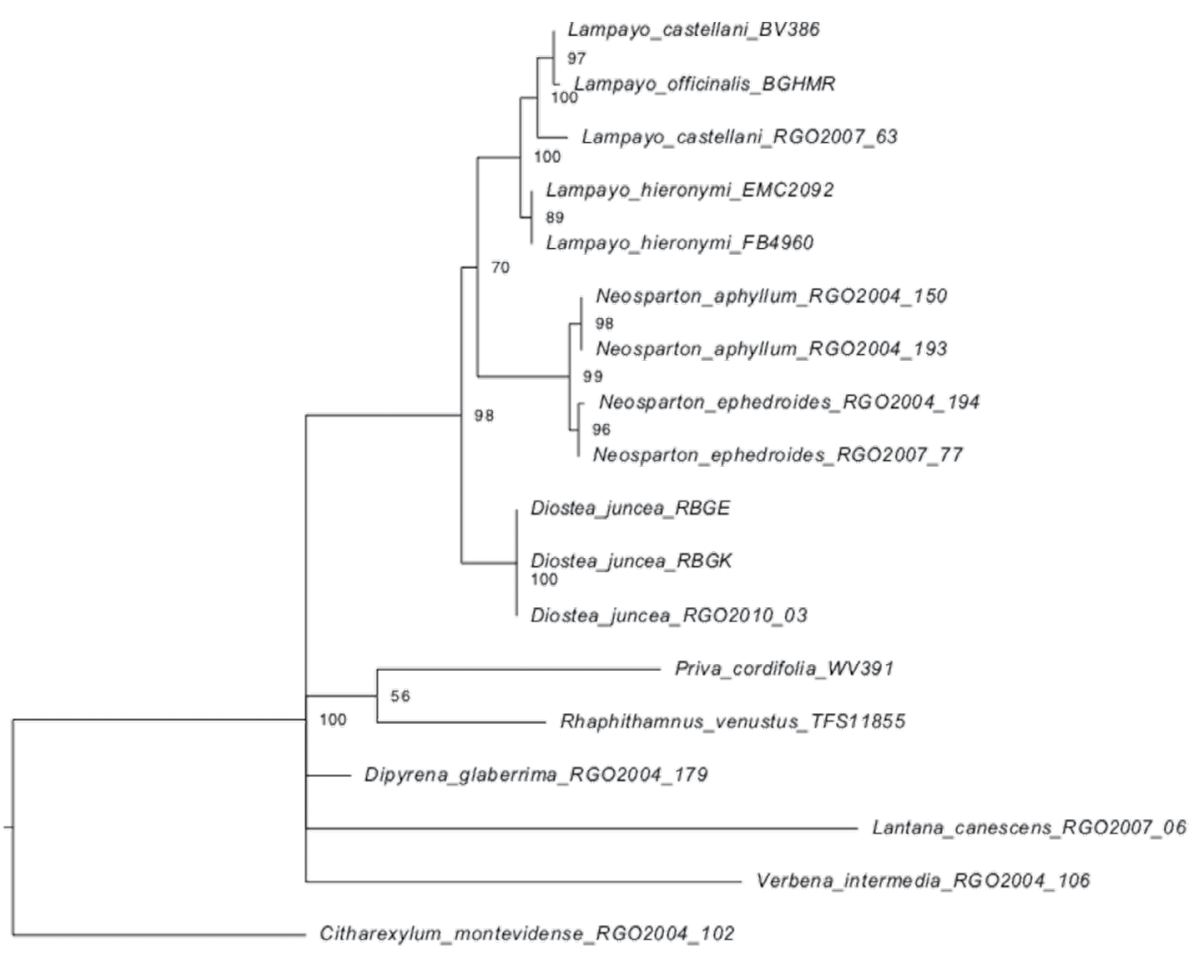

BI

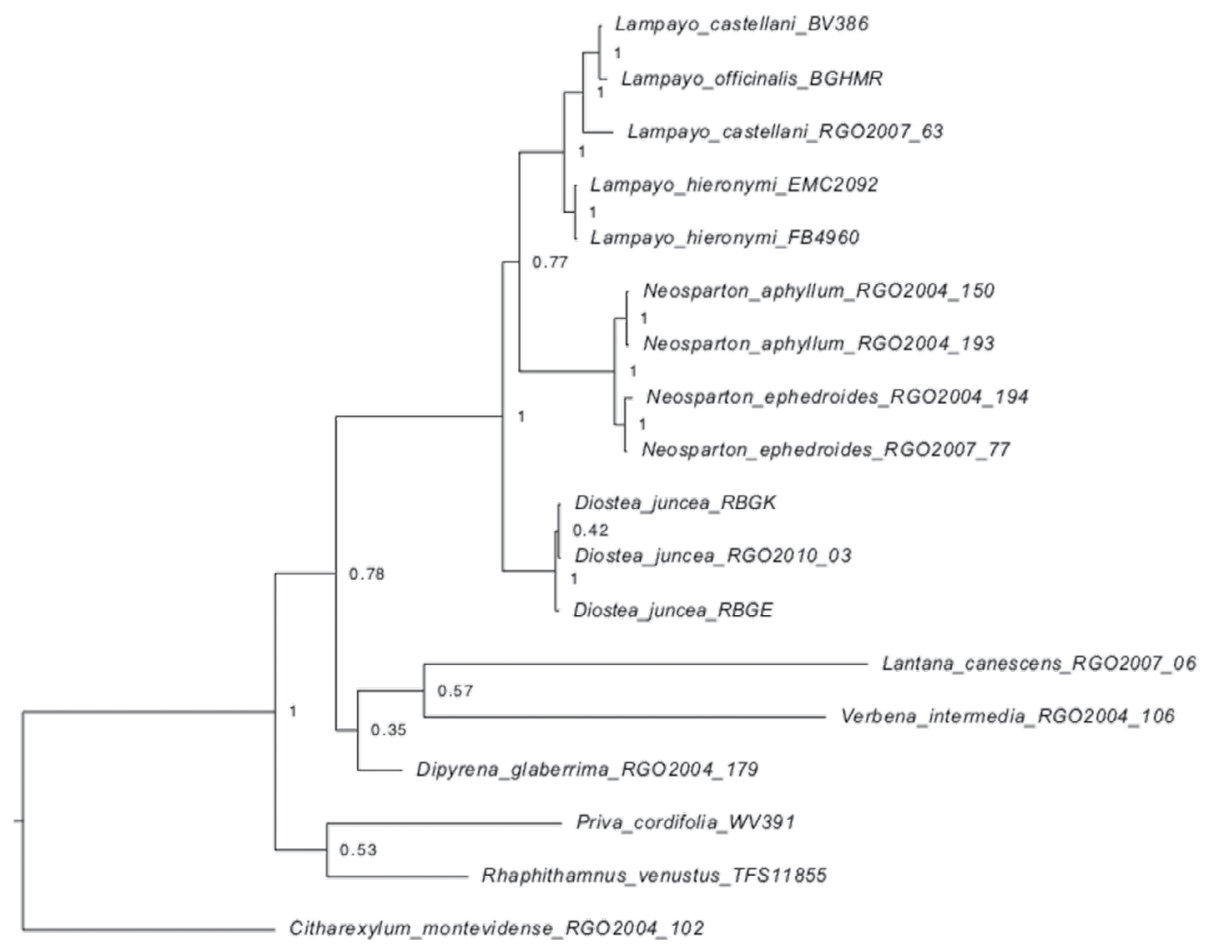

Fig. S2. Maximum likelihood tree (above) and Bayesian tree (below) for concatenated ITS/ETS loci. 
DARWINIANA, nueva serie 7(2): 305-324. 2019

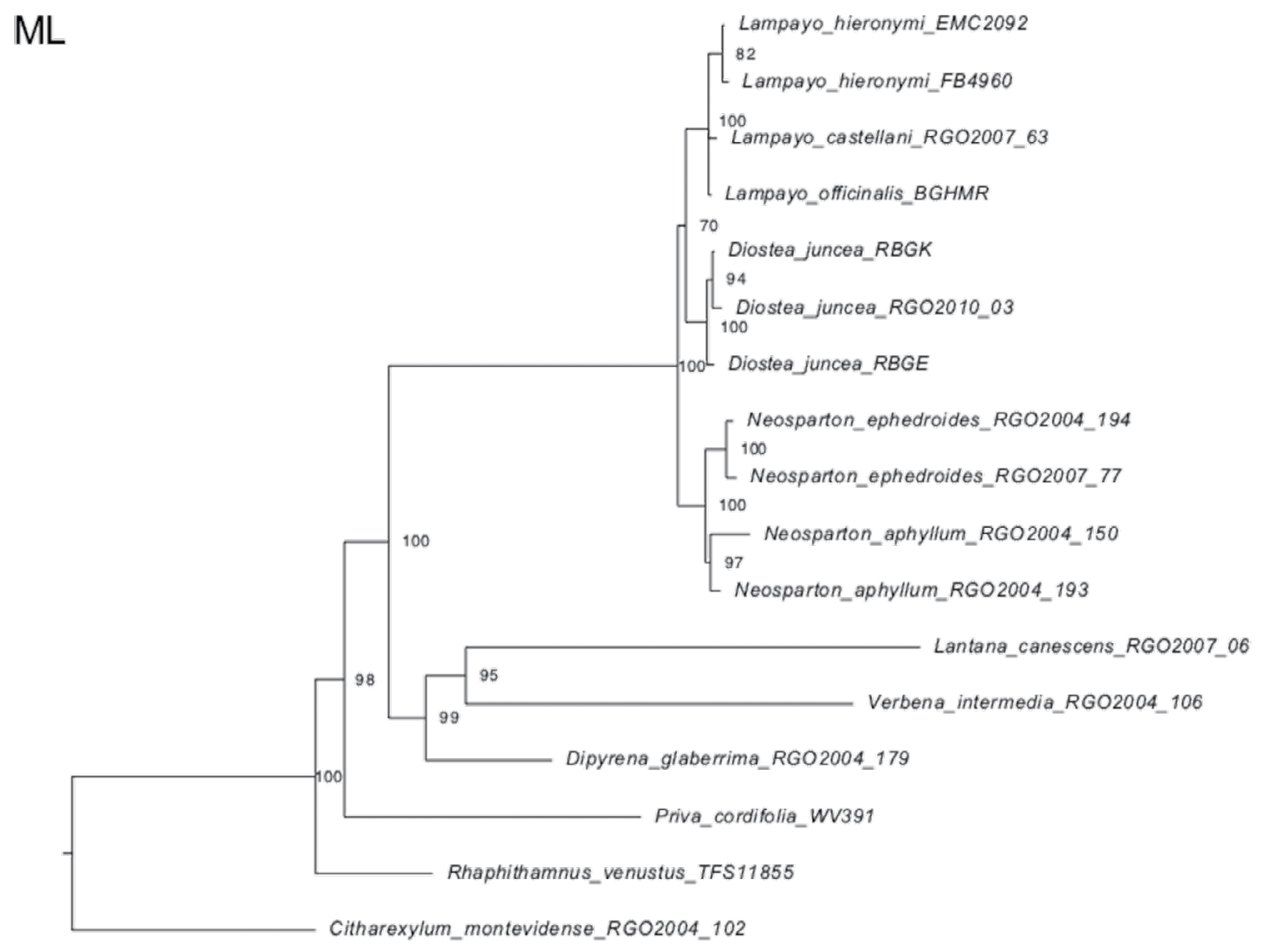

$\mathrm{BI}$

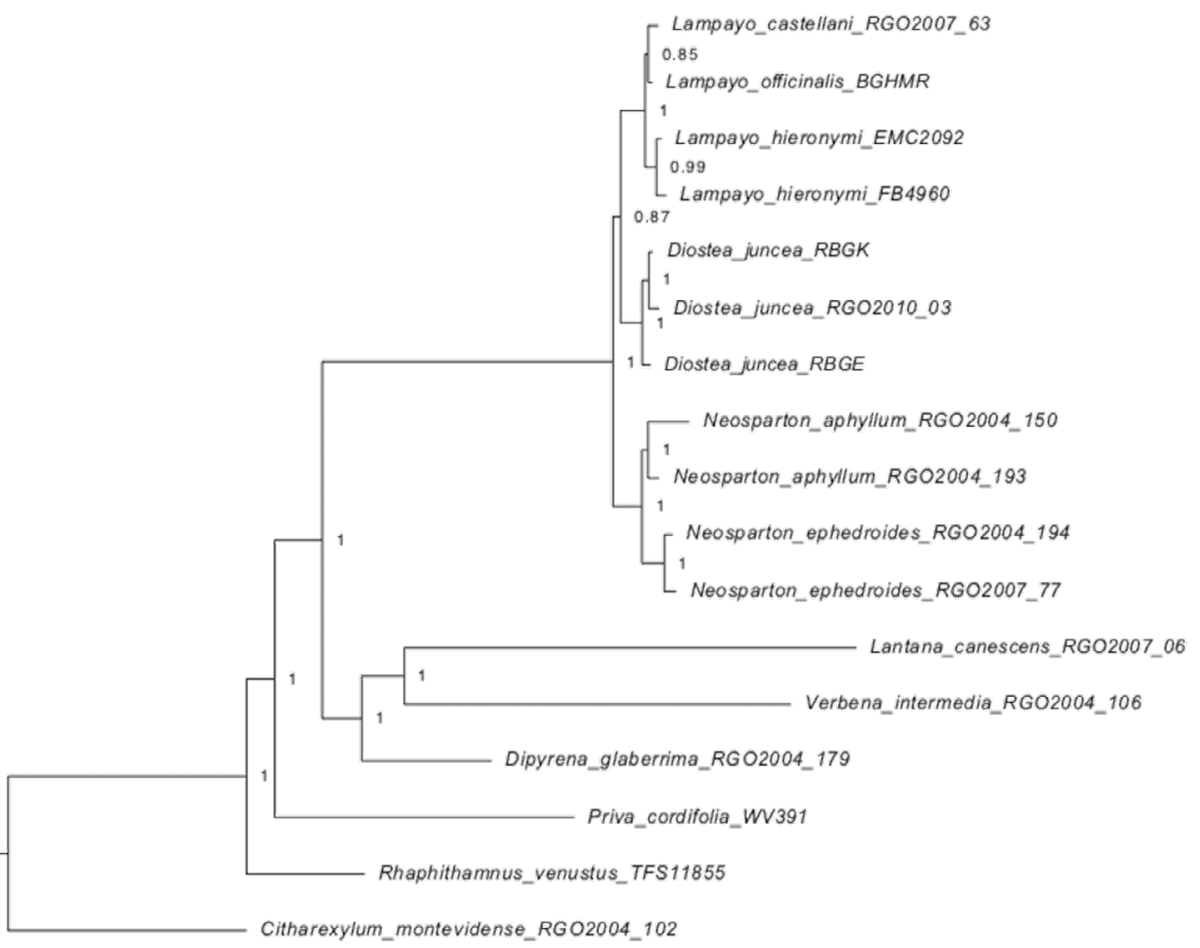

Fig. S3. Maximum likelihood tree (above) and Bayesian tree (below) for concatenated PPR loci. 


\section{LU ET AL. Phylogeny of Neospartoneae (Verbenaceae)}

$\mathrm{ML}$

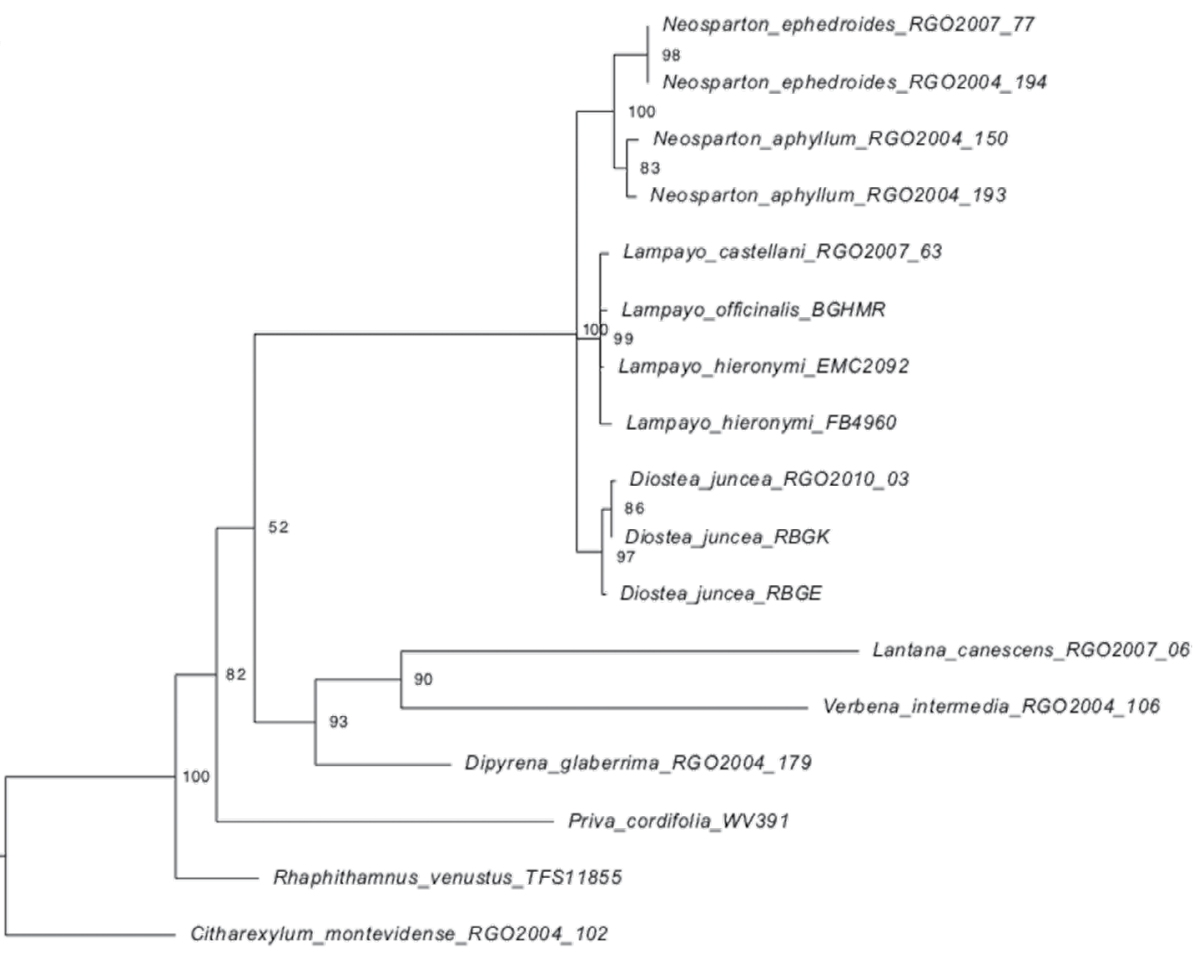

$\mathrm{BI}$

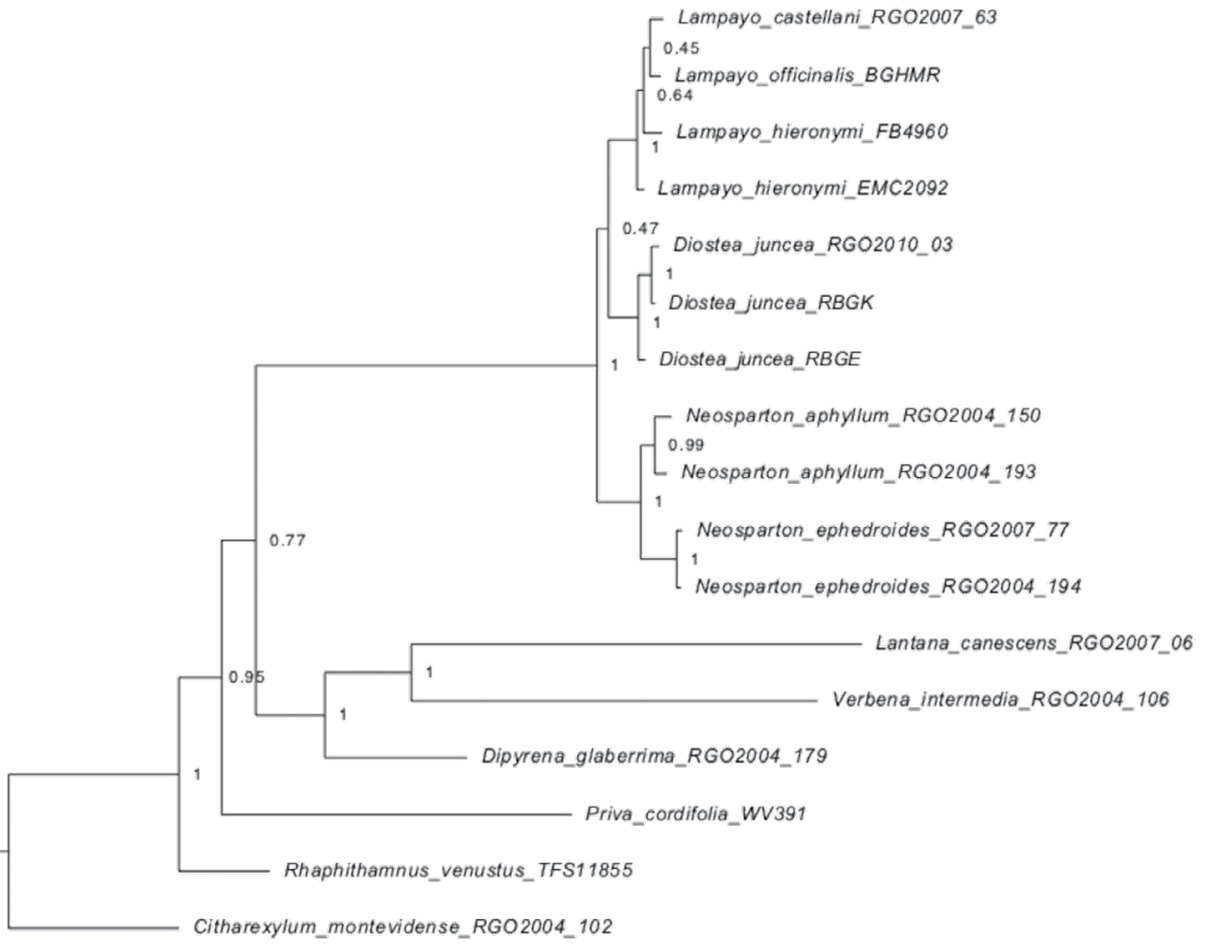

Fig. S4. Maximum likelihood tree (above) and Bayesian tree (below) for PPR 11 locus. 
DARWINIANA, nueva serie 7(2): 305-324. 2019

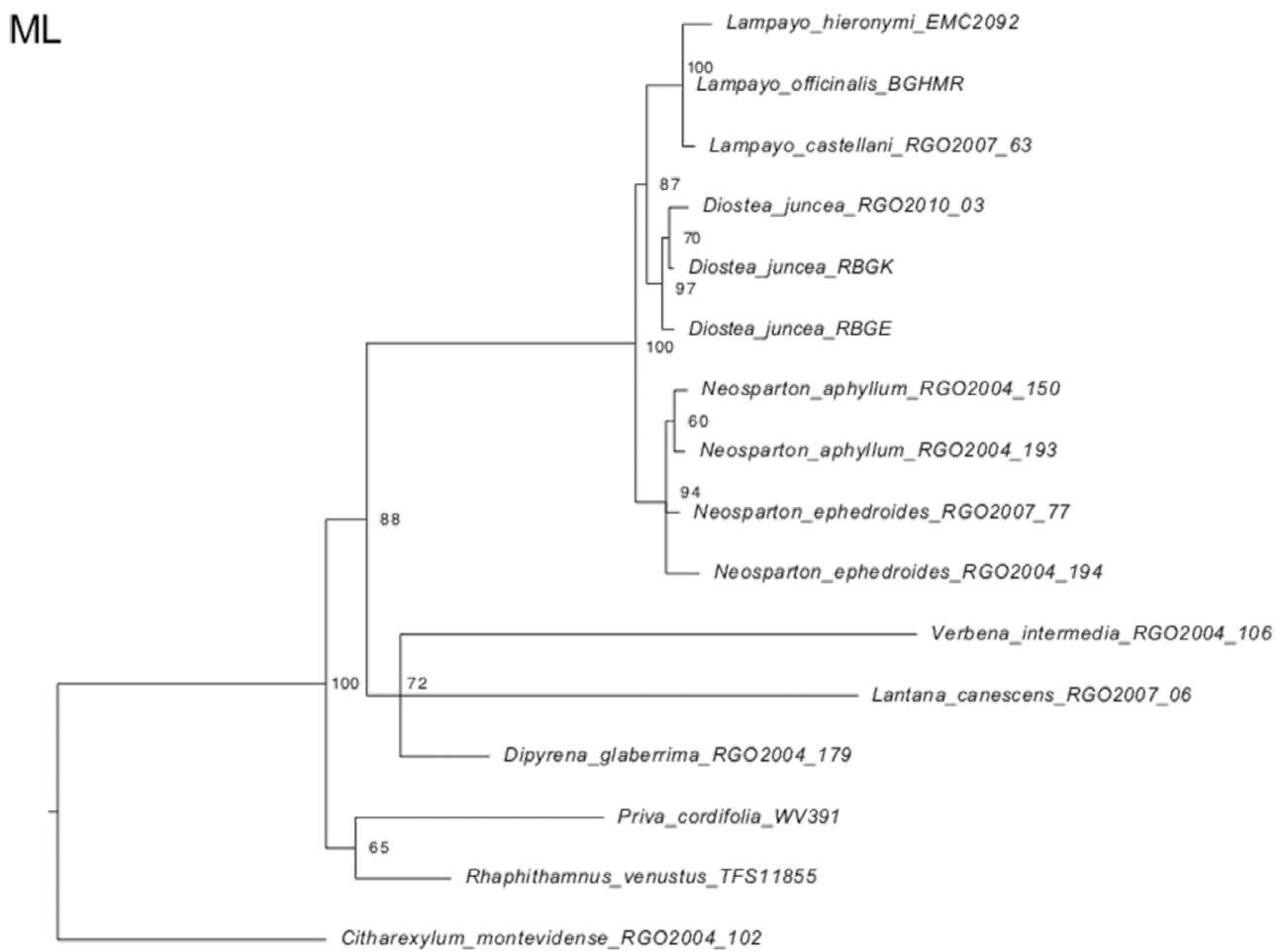

$\mathrm{BI}$

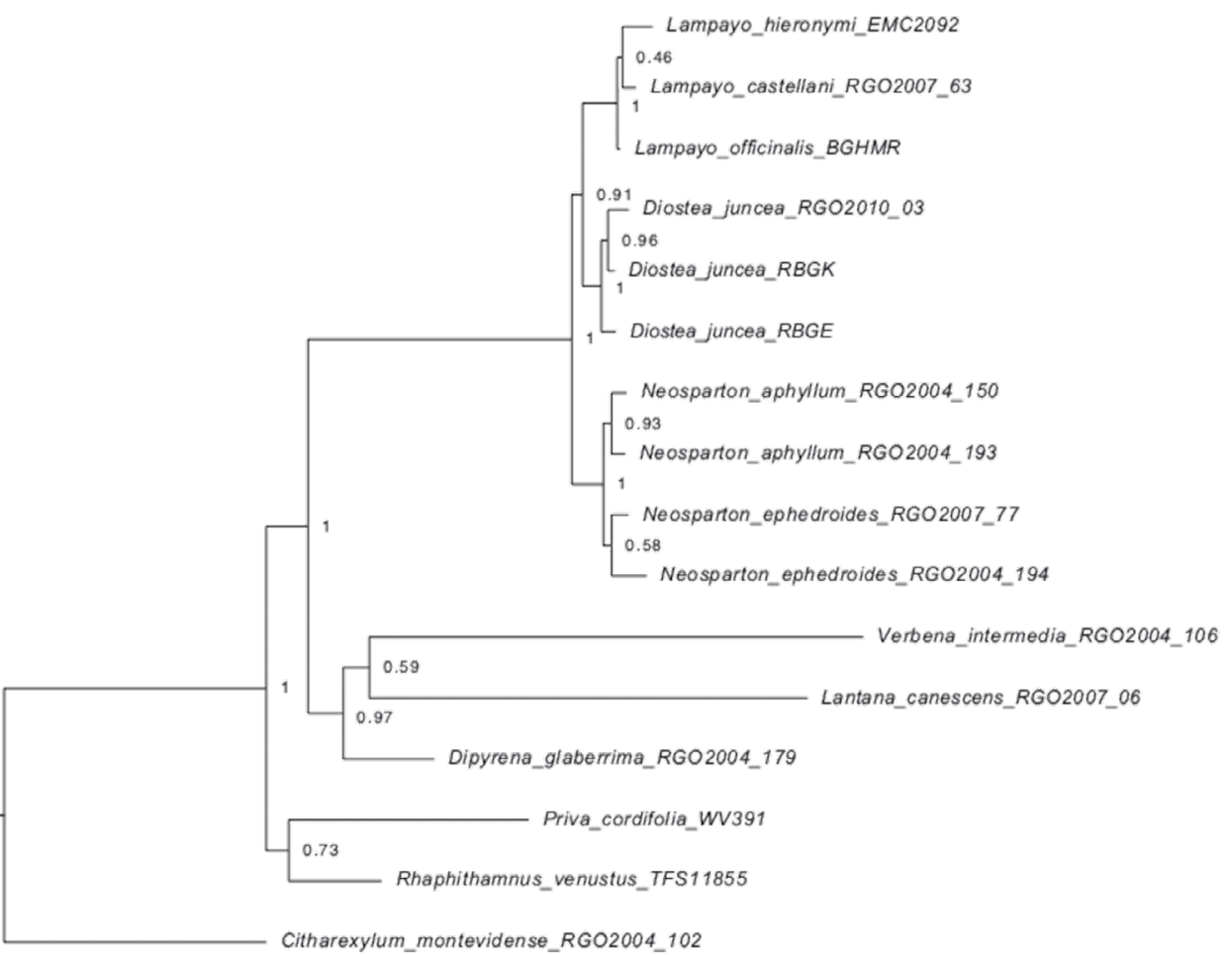

Fig. S5. Maximum likelihood tree (above) and Bayesian tree (below) for PPR 70 locus. 
M. LU ET AL. Phylogeny of Neospartoneae (Verbenaceae)

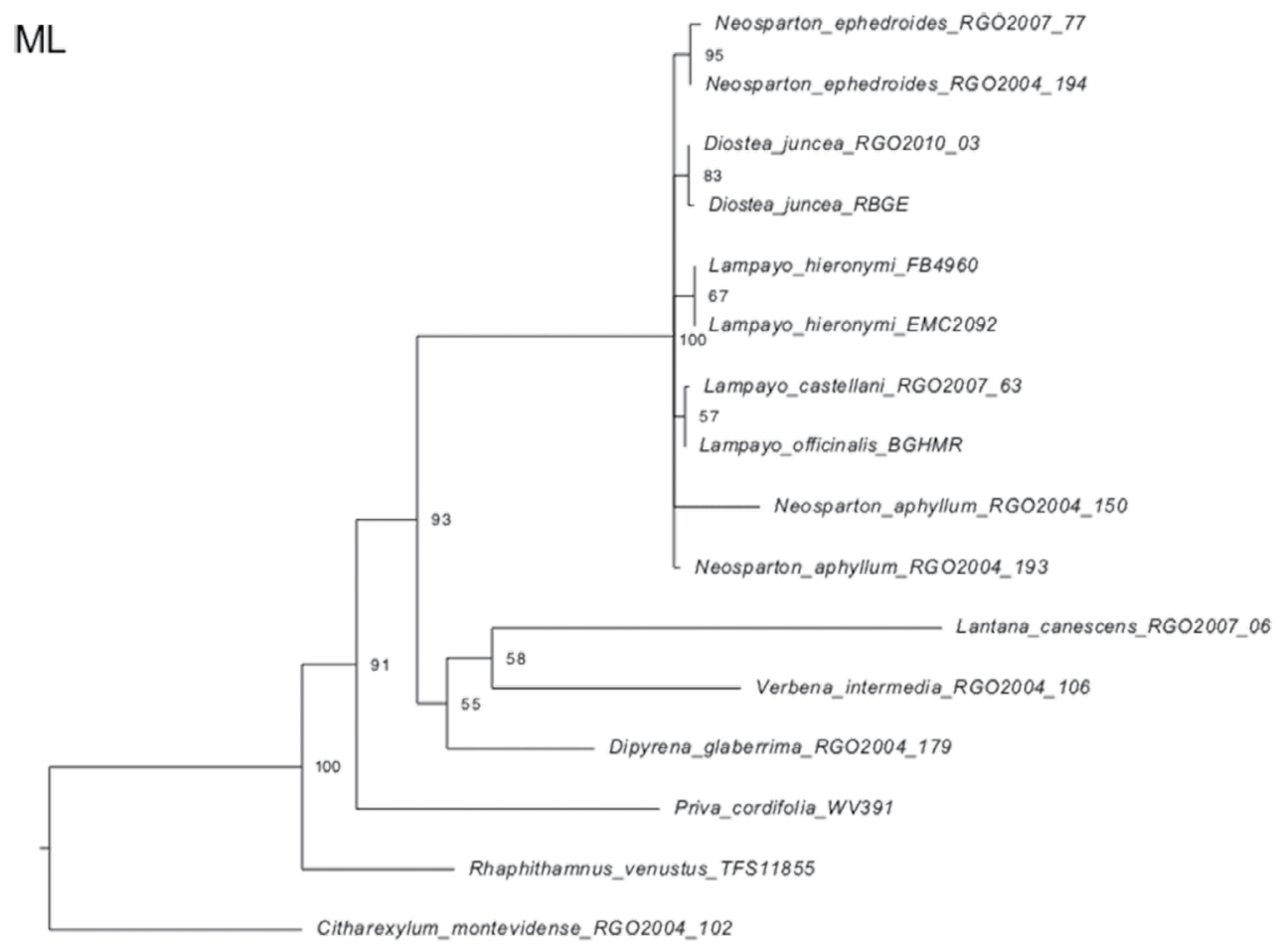

BI

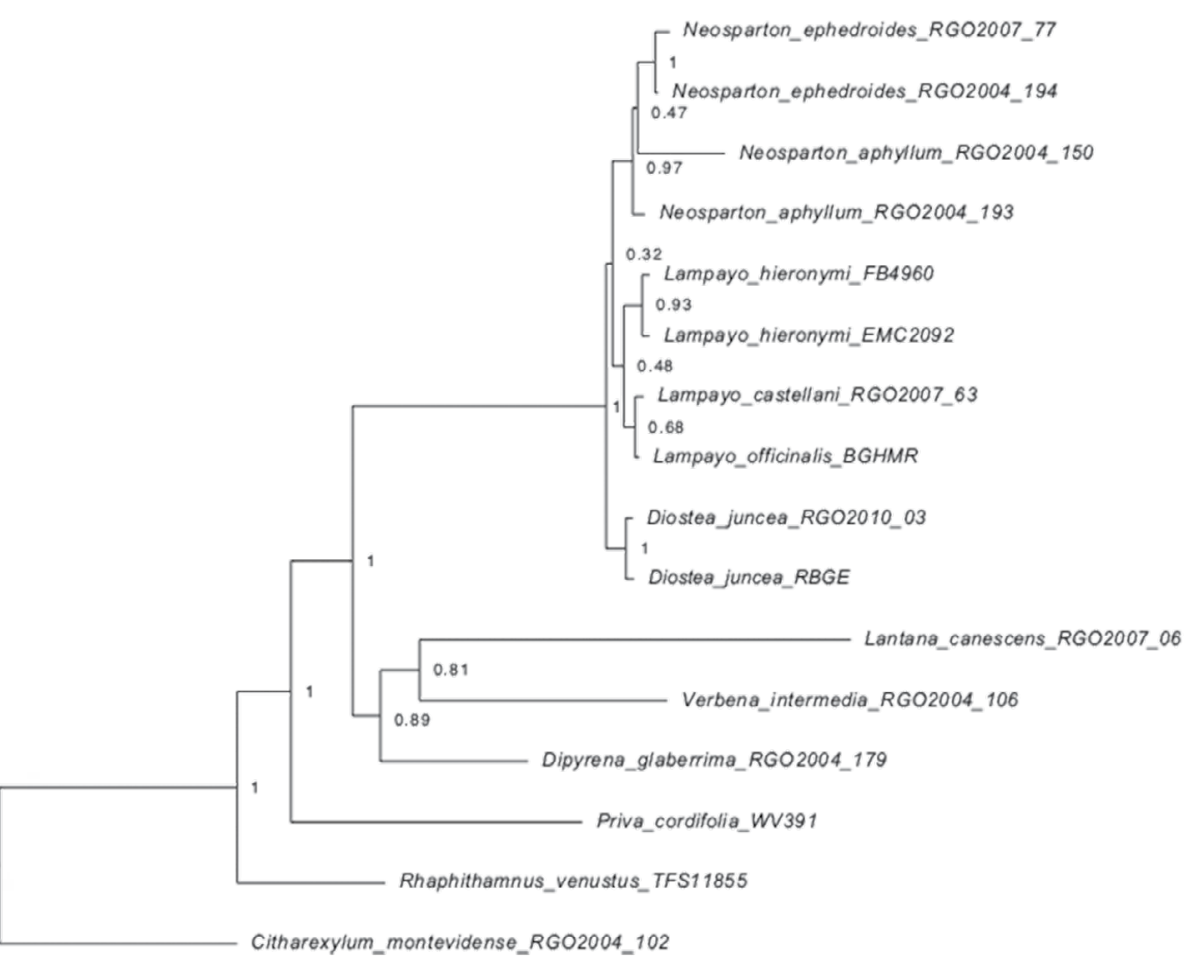

Fig. S6. Maximum likelihood tree (above) and Bayesian tree (below) for PPR 123 locus. 

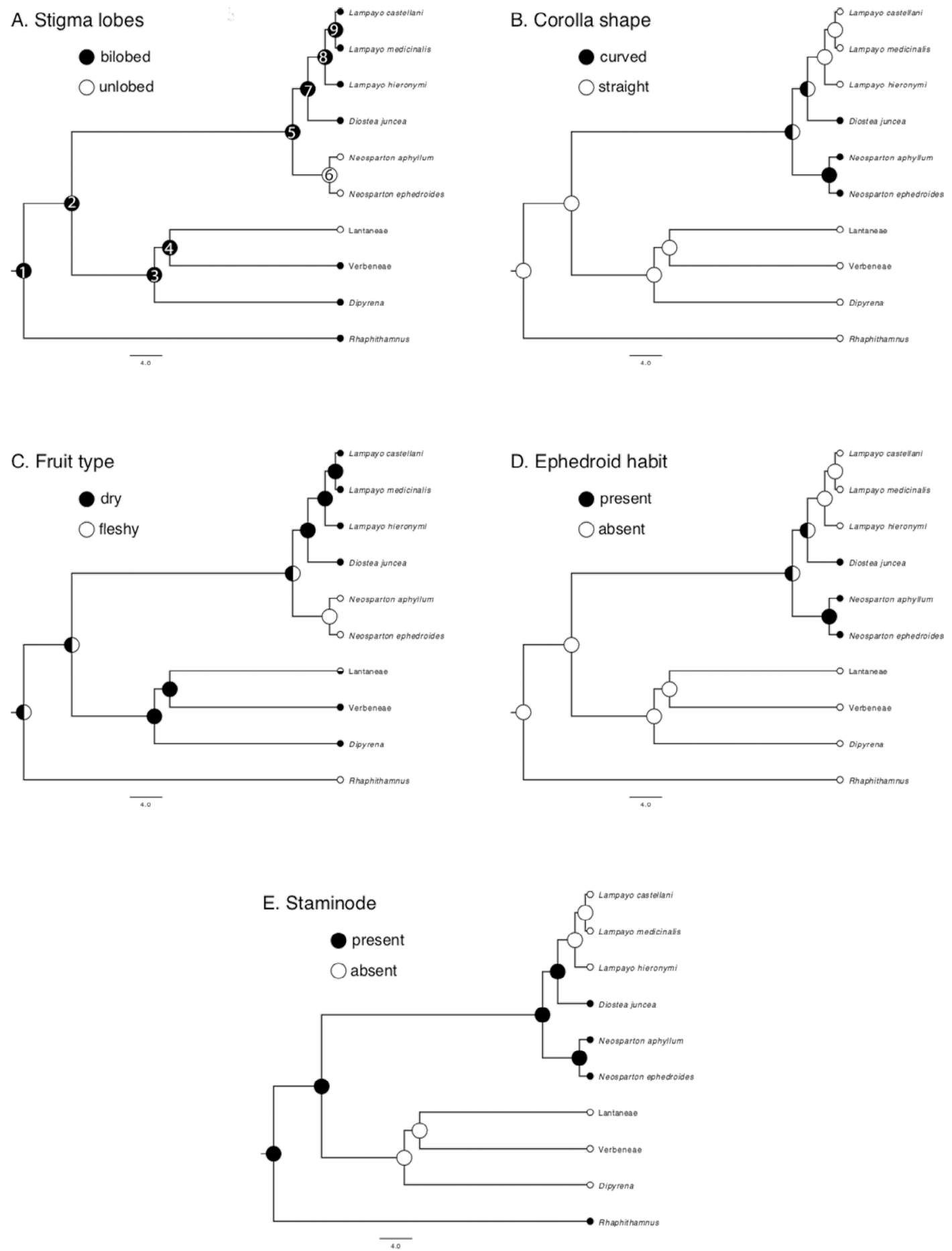

Fig. S7. Maximum parsimony reconstructions for A, stigma lobes. B, corolla shape. C, fruit type. D, ephedroid habit. E, staminodes. Node numbers in panel (A) correspond to node numbers in Supplementary Table 1. Small circles at tips show how individuals were coded (black $=$ present, white $=$ absent). Large circles at interior nodes display character state reconstructed at that node. Nodes with both black and white had ambiguous reconstructions. 